\title{
Chemical interaction of dual-fuel mixtures in low-temperature oxidation, comparing $n$-pentane/dimethyl ether and $n$-pentane/ethanol
}

\author{
Hanfeng Jin a,b,1, Julia Pieper ${ }^{a, 1}$, Christian Hemken ${ }^{a, c}$, Eike Bräuer ${ }^{a}$, Lena Ruwe \\ Katharina Kohse-Höinghaus ${ }^{\mathrm{a}, *}$ \\ a Department of Chemistry, Bielefeld University, Universitätsstraße 25, 33615 Bielefeld, Germany \\ ${ }^{\mathrm{b}}$ Center for Clean Combustion Research, KAUST, Thuwal 23955-6900, Saudi Arabia \\ c Physico Chemical Fundamentals of Combustion, RWTH Aachen University, Schinkelstraße 8, 52062 Aachen, Germany
}

\section{A R T I C L E I N F O}

\section{Article history:}

Received 12 January 2018

Revised 15 February 2018

Accepted 2 March 2018

Available online $\mathrm{xxx}$

\section{Keywords:}

Dual-fuel strategy

Low-temperature oxidation

Chemical interaction

$n$-pentane

Dimethyl ether

Ethanol

EI-MBMS

Flow reactor

\begin{abstract}
A B S T R A C T
With the aim to study potential cooperative effects in the low-temperature oxidation of dual-fuel combinations, we have investigated prototypical hydrocarbon $\left(\mathrm{C}_{5} \mathrm{H}_{12}\right) /$ oxygenated $\left(\mathrm{C}_{2} \mathrm{H}_{6} \mathrm{O}\right)$ fuel mixtures by doping $n$-pentane with either dimethyl ether (DME) or ethanol (EtOH). Species measurements were performed in a flow reactor at an equivalence ratio of $\phi=0.7$, at a pressure of $p=970$ mbar, and in the temperature range of 450-930 K using electron ionization molecular-beam mass spectrometry (EI-MBMS). Series of different blending ratios were studied including the three pure fuels and mixtures of $n$-pentane containing $25 \%$ and $50 \%$ of $\mathrm{C}_{2} \mathrm{H}_{6} \mathrm{O}$. Mole fractions and signals of a significant number of species with elemental composition $\mathrm{C}_{\mathrm{n}} \mathrm{H}_{2 \mathrm{n}+\mathrm{x}} \mathrm{O}_{\mathrm{y}}(n=1-5, x=0-(n+2), y=0-3)$ were analyzed to characterize the behavior of the mixtures in comparison to that of the individual components. Not unexpectedly, the overall reactivity of $n$-pentane is decreased when doping with ethanol, while it is promoted by the addition of DME. Interestingly, the present experiments reveal synergistic interactions between $n$-pentane and DME, showing a stronger effect on the negative temperature coefficient (NTC) for the mixture than for each of the individual components. Reasons for this behavior were investigated and show several oxygenated intermediates to be involved in enhanced $\mathrm{OH}$ radical production. Conversely, ethanol is activated by the addition of $n$-pentane, again involving key $\mathrm{OH}$ radical reactions. Although the main focus here is on the experimental results, we have attempted, in a first approximation, to complement the experimental observations by simulations with recent kinetic models. Interesting differences were observed in this comparison for both, fuel consumption and intermediate species production. The inhibition effect of ethanol is not predicted fully, and the synergistic effect of DME is not captured satisfactorily. The exploratory analysis of the experimental results with current models suggests that deeper knowledge of the reaction chemistry in the low-temperature regime would be useful and might contribute to improved prediction of the low-temperature oxidation behavior for such fuel mixtures.
\end{abstract}

(c) 2018 The Combustion Institute. Published by Elsevier Inc. All rights reserved.

\section{Introduction}

Adverse effects on the environment and climate caused by the combustion of fossil fuels in conventional engines underline the need for more efficient and cleaner engine-fuel combinations [1,2]. Fuel additives as a component of intelligent fuel design can serve to control the ignition timing in advanced engine concepts using homogeneous charge compression ignition ( $\mathrm{HCCl})$, reactivity-

* Corresponding author at: Department of Chemistry, Bielefeld University, Universitätsstraße 25, 33615 Bielefeld, Germany.

E-mail addresses: hanfeng.jin@kaust.edu.sa (H. Jin), kkh@uni-bielefeld.de (J. Pieper).

1 They both contributed equally to this work. controlled compression ignition (RCCI), and stratified-charge compression ignition (SCCI), with the prospect of cleaner burning processes and higher thermal efficiencies [3,4]. However, the operation of such engine-fuel combinations must rely on the fundamental knowledge of the combustion chemistry that drives the lowtemperature auto-ignition of fuel mixtures. Such low-temperature combustion (LTC) strategies can involve mixtures of high-cetane and high-octane fuels with their synergistic combustion characteristics to achieve high thermal efficiencies, and several approaches have been demonstrated, e.g. using primary reference fuels with additives to achieve efficient engine control and ignition timing $[5,6]$. High-cetane fuels usually auto-ignite early, showing typical low-temperature heat release (LTHR) and high-temperature heat release (HTHR) characteristics. The addition of high-octane fuels 
suppresses the early LTHR, shifting more of the heat release from high-cetane fuels closer to the top dead center of engines, thereby improving the combustion efficiency in internal combustion engines.

Dual-fuel mixtures are a good basis to understand the chemistry of multi-component mixtures. In spite of its importance for practical applications in engines, however, detailed information regarding potential interactions between different fuel components in the LTC regime remains scarce. The auto-ignition of mixtures with simple molecular structures was investigated recently $[7,8]$, including methane/dimethyl ether (DME) and propane/DME blends. These studies have profited from the numerous lowtemperature oxidation investigations of light $\mathrm{C}_{3}-\mathrm{C}_{4}$ alkanes [8-18] as a substantial basis to examine dual-fuel interactions. Regarding heavier alkanes, $n$-heptane/ethanol (EtOH) blends were investigated by Saisirirat et al. $[19,20]$ under HCCI and jet-stirred reactor (JSR) conditions, with a noted impact of $n$-heptane on ethanol consumption between 600 and $700 \mathrm{~K}$. Their work mainly focused on ignition delay times, however, and only a few intermediates were observed which could not illustrate the nature of the interaction between $n$-heptane and ethanol $[19,20]$. A challenge to fully understand such interactive effects for fuels of the size of $n$-heptane or iso-octane is the large number of isomeric structures that are formed in the low-temperature oxidation reactions via alkyl (R), peroxyalkyl (ROO), and hydroperoxyalkyl (QOOH) radicals. The identification and quantification of these radicals and their subsequent reaction products are often beyond the capability of commonly used diagnostic techniques. Furthermore, significant uncertainties exist in the pressure-dependent kinetic parameters of these reactions [21-25] which limit the further development of accurate kinetic models. As a reasonable compromise, we have therefore chosen $n$-pentane $\left(\mathrm{C}_{5} \mathrm{H}_{12}\right)$, an alkane component in gasoline, as the primary fuel in this work to explore its interaction with fuel additives of different ignition reactivity.

As for lighter or heavier alkanes [8-18,21-25], a number of studies have been performed of the low-temperature oxidation of n-pentane, using rapid compression machine (RCM) [26-35], shock tube (ST) [34-36], and JSR [37-40] experiments. Most of the previous experimental work focused on the macroscopic auto-ignition behavior of $n$-pentane, with detailed speciation reported only in recent publications of Bugler et al. [39] and Rodriguez et al. [40]. Bugler et al. [39] have also developed a mechanism for the autoignition of pentane isomers which they examined against JSR data (500-1100 K, 1 and $10 \mathrm{~atm}$ ) obtained by gas chromatography (GC), cavity ring-down spectroscopy (CRDS), and Fourier transform infrared spectroscopy (FTIR). Rodriguez et al. [40] complemented the atmospheric-pressure JSR experiments in the temperature range of Bugler et al. [39] with measurements using synchrotron vacuum ultraviolet photoionization mass spectrometry (SVUV-PIMS). Their experiment successfully identified and separated contributions of different isomers, especially of saturated, unsaturated, and carbonyl hydroperoxides. These recent investigations support the choice of $n$-pentane as base fuel for the present work.

DME and ethanol have been selected as isomeric fuel additives of different reactivity in this study. They are considered as potential or widely applied biofuels that could reduce the emission of air pollutants $[1,41,42]$. DME has been used as a fuel additive or alternative fuel in compression ignition engines because of its excellent auto-ignition characteristics [43]. It has a high cetane number $(\mathrm{CN}=55)$ and was found to be an excellent ignition improver for HCCI engines $[44,45]$. The present knowledge on these two isomeric fuels' low-temperature oxidation reactions is more detailed for DME than for ethanol. Experimental investigations, including ignition delay [7,46] and speciation [41,47-54] measurements in JSRs and flow reactors have laid an extensive foundation for DME's reaction kinetics. Quantum chemical calculations were performed for both the first and second $\mathrm{O}_{2}$ addition reactions, as well as the further reactions of the $\mathrm{CH}_{3} \mathrm{OCH}_{2} \mathrm{O}_{2}$ (ROO) and $\mathrm{CH}_{2} \mathrm{OCH}_{2} \mathrm{OOH}(\mathrm{QOOH})$ intermediates [55]. The pressure-dependent description for these reactions is sensitive to the low-temperature oxidation of DME [56], which was well considered in the recently published DME models of Burke et al. [7] and Rodriguez et al. [57]. Very recently, Jiang et al. [58] determined ignition delay times of $n$-pentane/DME mixtures and their experimental results compared favorably to the pentane isomer model by Bugler et al. [35]. The situation for a detailed study including reactive intermediates of $n$-pentane/DME interactive mixture effects in the LTC regime attempted here should thus be considered favorable.

Ethanol is a commonly used additive to fossil transportation fuels. Different from DME, ethanol has a high research octane number $(\mathrm{RON}=109$ [59]) and displays single-stage ignition. Compared to ample studies on the high-temperature combustion of ethanol, its low-temperature oxidation chemistry has attracted lesser attention [51,60-63]. Haas et al. [61] and Herrmann et al. [51] studied the oxidation of pure ethanol in flow reactor conditions with somewhat different results. Very weak negative temperature coefficient (NTC) behavior might have been observed for the rich ethanol $/ \mathrm{O}_{2} / \mathrm{Ar}$ mixture by Herrmann et al. [51] as evident from their Fig. 3a, but not in the work of Haas et al. [61]. The model of Cancino et al. [60] also showed a slight NTC behavior in the reproduction of Herrmann et al.'s data [51], but no further studies confirmed these results. Recognizing these difficulties, ethanol auto-ignition has been investigated very recently for ST and RCM conditions by adding DME as a radical initiator [64].

Regarding this background, it is to be expected that $n$-pentane will exhibit different global NTC behavior when blended with either isomer of $\mathrm{C}_{2} \mathrm{H}_{6} \mathrm{O}$, namely DME or ethanol. However, there is a lack of prior information on the detailed oxidation reactions and intermediate species mole fractions or on any potential interactions between the two fuels in such mixtures. We therefore provide speciation experiments in a flow reactor for both, the dual-fuel mixtures of $n$-pentane/DME and $n$-pentane/EtOH, at nearatmospheric pressure and in the temperature range of $450-930 \mathrm{~K}$. The species composition along the reaction progress was analyzed using electron ionization molecular-beam mass spectrometry (EIMBMS). The results for the mixtures were compared to the behavior of each individual fuel component. Temperature-resolved, extensive species information has thus been obtained systematically regarding synergistic or antagonistic effects between these fuels of different reactivity, and combined with an analysis of the detailed chemical oxidation pathways.

Although the main emphasis in the present work is on the experimental results, we have complemented the measured species data with initial simulations by two recent kinetic models. Specifically, we have used the model for pentanes of the Galway group [39] and the recent update of the Polimi mechanism [17]. Discrepancies between experiment and simulation were noted and are discussed in an attempt to improve the understanding of the low-temperature oxidation mechanisms for these mixtures including interactive effects.

\section{Experimental and numerical approaches}

\subsection{Flow reactor experiment}

The low-temperature oxidation reactions of $n$-pentane, DME, ethanol, and the respective dual-fuel mixtures were investigated in a flow reactor in the temperature regime of $450-930 \mathrm{~K}$ (step size $\Delta T=5 \mathrm{~K}$ ), keeping several important parameters constant. The experiments were consistently performed at $\phi=0.7,970 \mathrm{mbar}$, a total cold gas flow rate of $300 \mathrm{sccm}$ (standard cubic centimeters per minute at $1 \mathrm{~atm}$ and $273.15 \mathrm{~K}$ ), and an argon dilution of $90 \%$.
88 
Table 1

Experimental conditions; $\gamma$ is the fraction of $n$-pentane in the mixture: $\gamma=x_{\mathrm{C} 5 \mathrm{H} 12} /\left(x_{\mathrm{C} 5 \mathrm{H} 12}+x_{d}\right), d$ : DME or EtOH.

\begin{tabular}{|c|c|c|c|c|c|c|c|c|c|c|}
\hline \multirow[t]{2}{*}{ Fuel } & \multirow[t]{2}{*}{ Name } & \multirow[t]{2}{*}{$\mathrm{P}$ (bar) } & \multirow[t]{2}{*}{$\phi$} & \multirow[t]{2}{*}{$\gamma$} & \multicolumn{6}{|c|}{ Gas flow rate $(\mathrm{sccm})$, std. $273.15 \mathrm{~K}, 1 \mathrm{~atm}$} \\
\hline & & & & & Total & $\mathrm{Ar}$ & $\mathrm{O}_{2}$ & $\mathrm{C}_{5} \mathrm{H}_{12}$ & DME & $\overline{\mathrm{EtOH}}$ \\
\hline$n$-Pentane $\left(\mathrm{C}_{5} \mathrm{H}_{12}\right)$ & P100 & 0.97 & 0.7 & & 300.0 & 270.0 & 27.59 & 2.414 & & \\
\hline Dimethyl ether (DME) & D100 & 0.97 & 0.7 & & 300.0 & 270.0 & 24.32 & & 5.676 & \\
\hline Ethanol (EtOH) & E100 & 0.97 & 0.7 & & 300.0 & 270.0 & 24.32 & & & 5.676 \\
\hline \multirow[t]{2}{*}{$\mathrm{C}_{5} \mathrm{H}_{12} / \mathrm{DME}$ mixtures } & PD75 & 0.97 & 0.7 & 0.75 & 300.0 & 270.0 & 27.18 & 2.114 & 0.705 & \\
\hline & PD50 & 0.97 & 0.7 & 0.50 & 300.0 & 270.0 & 26.61 & 1.694 & 1.694 & \\
\hline \multirow{2}{*}{$\mathrm{C}_{5} \mathrm{H}_{12} /$ EtOH mixtures } & PE75 & 0.97 & 0.7 & 0.75 & 300.0 & 270.0 & 27.18 & 2.114 & & 0.705 \\
\hline & PE50 & 0.97 & 0.7 & 0.50 & 300.0 & 270.0 & 26.61 & 1.694 & & 1.694 \\
\hline
\end{tabular}

A lean stoichiometry was chosen due to the importance of lean and efficient burning and of the influences of high amounts of oxygen for the formation of oxygenated species. Electron ionization molecular-beam mass spectrometry was employed to identify the species composition. A detailed description of the experimental set-up, including both the reactor and mass spectrometry technique, has been reported earlier $[41,51,52]$ so that only some details of importance for the present experiment are given here.

The reactor is a fused silica tube with an inner diameter of $8 \mathrm{~mm}$. Its total length is $1.4 \mathrm{~m}$, with a heating area of $1.3 \mathrm{~m}$ that is divided into 8 independently regulated zones [65]. These are heated using an electrical furnace and are controlled by $\mathrm{Ni}-\mathrm{Cr} / \mathrm{Ni}$ thermocouples at the outside wall of the reactor. The exhaust gas from the reactor is extracted with a quartz nozzle (50 $\mu \mathrm{m}$ orifice) at the reactor exit and guided via a copper skimmer and a twostage differential pumping system into the ionization chamber of the mass spectrometer. Molecules are then ionized by a $17 \mathrm{eV}$ electron beam and detected by their time of flight with a resolution of $m / \Delta m \approx 2200$, enabling the separation of hydrocarbon and oxygenated species of the same nominal mass.

The inlet conditions for the oxidation experiments are listed in Table 1 and address the three individual fuels as well as two sets each of $n$-pentane mixtures with DME or EtOH. $n$-Pentane $(\geq 99 \%)$ was supplied by ChemSolute, and ethanol $(\geq 99.96 \%)$ was provided by VWR Chemicals. Gases were obtained from Linde AG, including dimethyl ether ( $\geq 99.9 \%), O_{2}(\geq 99.5 \%)$, and $\operatorname{Ar}(\geq 99.996 \%)$. The fraction of $n$-pentane in the mixture is expressed as $\gamma$ in Table 1 . The delivery of $n$-pentane and ethanol relied on a dialysis pump (Protea PM-1000) providing flow rates in the $\mu \mathrm{l} / \mathrm{min}$ range with uncertainties of $1 \%$. To prepare the respective mixtures, gases were metered by calibrated mass flow controllers (MKS Instruments, uncertainty $\sim 5 \%$ ), and liquid fuels were vaporized, mixed with the gases, and then preheated to $423 \mathrm{~K}$ prior to the reactor inlet.

Quantitative species mole fractions were determined whenever possible according to the procedure by Schenk et al. [66] using $\mathrm{Ar}$ as the reference. Following that work, the ratio of the integrated ion signal of a species to a reference signal is proportional to the ratio of their mole fractions, weighted by an energy-dependent calibration factor that includes a number of relevant experimental parameters. Here, the calibration factors for major species $\left(\mathrm{C}_{5} \mathrm{H}_{12}\right.$, DME, EtOH, $\mathrm{O}_{2}, \mathrm{H}_{2} \mathrm{O}, \mathrm{CO}$, and $\mathrm{CO}_{2}$ ) were determined from calibration with cold-gas samples and using the $\mathrm{C}, \mathrm{H}$, and $\mathrm{O}$ element balances at high-temperature equilibrium conditions. Intermediates were calibrated by simulating the signal ("convolution" method in [66]). The resulting uncertainties of mole fractions for major species are typically within $15 \%$, and those for intermediate species are within a factor of 2 , depending on the available cross section information from the literature. In cases where electron ionization cross sections or calibration information was not available as for some of the detected oxygenated species, relative species profiles are reported in terms of signal intensities normalized by the respective fuel inlet mole fraction to facilitate the analysis of trends between the behavior of individual mixture components and the mixtures. All experimental data reported in this work are provided in Supplementary Material 1 (SM1).

204

\subsection{Numerical simulation}

Simulations of the oxidation process in a laminar flow reactor have typically assumed a constant gas temperature or have relied on measured gas temperature profiles along the reactor, determined in non-reactive flows at identical reactor wall temperature $[41,49,67]$. Heat release in such reacting systems, typically approximated as negligible for highly diluted mixtures, is thus not considered, and consequently, negligible heat transfer between the reacting gas and the reactor wall is assumed, as no highly diluted conditions have been used here (10\% reactive mixture). This limit may not be applicable for less diluted conditions, especially since temperature is a very sensitive parameter in the low-temperature oxidation process. An accurate physical model of a laminar flow reactor should consider mass convection, mass diffusion, heat release of the reacting gas, thermal conductivity, and thermal exchange with the wall of the reactor.

Since this work is mainly focused on reporting experimental results, we provide only a first approximation of model predictions for the investigated conditions. The simulation of the flow reactor using the OpenSMOKE++ package [68] follows procedures by Refs. [51,65]. A multi-zone approach was used, dividing the reactor into a pre-heating zone $(14 \mathrm{~cm})$, a reaction zone $(111 \mathrm{~cm})$, and a cooling zone $(5 \mathrm{~cm})$. A time-resolved non-isothermal solution was applied. The temperature profile of the non-reacting argon flow was measured along the reactor at different heating temperatures, and the heat transfer coefficient $k$ for transfer between the heating furnace and the reacting gas through the flow reactor wall was evaluated by simulating a pure (non-reactive) argon flow. As a result, a coefficient of $k=10 \mathrm{~W} \mathrm{~m} \mathrm{~m}^{-2} \mathrm{~K}^{-1}$ was assigned for all reaction conditions. Details for the evaluation of $k$ are provided together with the measured and simulated gas temperature profiles (Fig. S1) in Supplementary Material 2 (SM2). We acknowledge that this approach may reach its limits for the reactive mixtures with very temperature-sensitive chemistry, and suggest that the assumptions made here should be tested with more refined models in the future that might consider two-dimensional effects and changing heat transfer depending on reaction conditions.

For the initial simulation, two recent mechanisms were chosen to explore the interaction between $n$-pentane and dimethyl ether or ethanol. The mechanism by Bugler et al. [39], here called the NUIG model, provides a low-temperature oxidation pentane submechanism, which was improved based on their previous model [35] and examined against ignition delay times and JSR experimental data. The DME and ethanol sub-mechanisms in the NUIG model were also comprehensively investigated in their former kinetic studies $[7,49,62]$. Also, we have chosen the long-term developing and regularly updated model by Ranzi et al. [17], here called Polimi model. Their recent improvements in the low-temperature oxidation chemistry were focused on the reaction of carbonyl-
207 208 209 210 211 212 
hydroperoxides and peroxy radicals [17,21]. In any case, comparisons of our experimental data reported here with model simulations should be regarded as an initial exploration focused mainly on the trends observed for the mixtures, with the aim to detect substantial deviations between experiment and model that may serve to guide further model development.

\section{Results and discussion}

In this section, experimental results are presented for the dualfuel mixtures and analyzed in consideration of those for the individual fuels. The main aim is to detect and contribute to understanding differences in reactivity and species formation in the lowtemperature regime with $n$-pentane as the base fuel upon addition of each of the two oxygenated isomers. In addition, initial modeling is performed for the three individual fuels and the mixtures to examine, in particular, their capability to reproduce the trends in the low-temperature oxidation behavior. Generally, we will limit the model analysis to the NUIG model [39], with some additional results given for the Polimi model [17], especially to illustrate differences in the prediction for the fuel mixtures. A species list of the NUIG model with all species discussed in this work can be found in Table S1 in SM2 with formula, model name, nomenclature and structure.

Section 3.1 will present the conversion of the individual fuels and the dual-fuel combinations. Section 3.2 will provide more detailed insight into the reaction pathways for the different fuel components by reporting temperature-dependent profiles of intermediate species with an emphasis on the behavior of the fuel mixtures. Section 3.3 will conclude with selected aspects of the lowtemperature chemistry of these dual-fuel combinations.

\subsection{Reactivity of dual-fuel mixtures}

Selected experimental results for the low-temperature oxidation of all individual fuels and fuel combinations listed in Table 1 are given in Fig. 1. It shows the consumption of fuel and $\mathrm{O}_{2}$ as well as the formation of $\mathrm{H}_{2} \mathrm{O}$ and permits a first inspection of the temperature-dependent oxidation behavior. All major species profiles are presented in Figs. S2-S8 in SM2 together with simulations with the NUIG and Polimi models. The profiles in Fig. 1 are presented with the same scale, and a thin broken line at $616 \mathrm{~K}$, the temperature for the low-temperature minimum of $n$-pentane consumption, is included to facilitate comparison.

As expected, both $n$-pentane and DME show a two-stage oxidation behavior ( $n$-pentane: $616 \mathrm{~K}$ and $830 \mathrm{~K}$, DME: $550 \mathrm{~K}$ and additional ignition at $750 \mathrm{~K}$ not in the focus here), while the consumption of ethanol starts only above $750 \mathrm{~K}$. The low-temperature minimum of the fuel mole fraction near $550 \mathrm{~K}$ for DME is significantly lower than for $n$-pentane at $616 \mathrm{~K}$. These temperatures compare quite well with the results of Herrmann et al. [51] for DME and ethanol (see also the Supplemental Material of that paper), and of Bugler et al. [39] for $n$-pentane, considering the slightly different conditions in those studies. Increasing addition of DME to $n$-pentane increases the reactivity and shifts the minimum to temperatures below that for pure $n$-pentane. Ethanol $/ n$-pentane mixtures show some low-temperature reaction already for PE50 as particularly evident from the $\mathrm{H}_{2} \mathrm{O}$ mole fraction with a peak near $625 \mathrm{~K}$, and further increasing reactivity for PE75, with minima shifted to higher temperatures than for pure $n$-pentane.

In Fig. 2, the interaction effects are visualized in more detail, showing only the fuel consumption curves including predictions with both models. The four panels (a-d) consider these effects with $n$-pentane as the base fuel to which increasing amounts of DME ( $a$ and $c$ ) and ethanol ( $b$ and d) are added. Every profile is normalized by the inlet mole fraction of $n$-pentane in the specific mixture to ensure comparability between the measurements. The bottom two panels (e and f) take an inverse perspective, with DME and ethanol as the respective basis and a corresponding normalization. Because of the normalization, identical profiles would be expected if no mixture effects occurred.

The enhancement of the reactivity of $n$-pentane by DME in panels ( $a$ and $c$ ) in Fig. 2 is quite well reproduced by both models. The experimental profiles are slightly shifted toward lower temperatures and may indicate a small trend of increasing lowtemperature fuel conversion (conversion $=1-$ consumption) that is, however, within the experimental uncertainty. In the NTC region, some differences are seen in the shape of the experimental profiles with increasing DME addition, and the recovery of the fuel mole fraction toward the initial value near $750 \mathrm{~K}$ is less pronounced for the PD50 mixture. The NUIG model reproduces the shape of the profile excellently for the pure $n$-pentane condition and catches the trends for all conditions quite well. With shifts to lower temperatures by about $12 \mathrm{~K}$ for PD75 and $22 \mathrm{~K}$ for PD50 and an increase in low-temperature fuel conversion, it slightly overpredicts the effect of DME on the reactivity. With the Polimi model, the predictions are closer to the experimental results, with shifts by about $8 \mathrm{~K}$ and $16 \mathrm{~K}$ to lower temperatures and almost identical fuel consumption in this regime, and a slightly better representation of the profiles also at higher temperatures. A tendency toward predicting two peaks can be noted in the NTC region for both the PD75 and PD50 mixtures. This effect is seen also in the major species curves in Figs. S5 and S6 in SM2. The reason for this behavior seems to be related to the representation of heat transfer in the numerical simulation (see Section 2.2), since exploratory modeling results for these two neat fuels and their mixtures without considering the heat release of the reacting gases (Figs. S9-S12 in SM2) do not show this two-peak behavior. As explained above in Section 2.2, the present modeling results should be considered as a first approximation, awaiting a more full description of twodimensional effects and changing heat release that is, however, beyond the present study with a mainly experimental focus.

As seen in Fig. 2b and d, the addition of ethanol significantly inhibits the consumption of $n$-pentane in contrast to the effect of DME. It shifts the consumption temperature to a higher region, narrows the temperature window of the NTC zone, and significantly reduces the maximum fuel conversion. Both models can well reproduce the $n$-pentane profile for the PE75 mixture but fail for PE50. The measured maximum conversion of $n$-pentane in PE50 is near $40 \%$, while the NUIG model predicts only about $20 \%$ and the Polimi model shows only very weak low-temperature reaction.

Instead of focusing on $n$-pentane as the base fuel to which DME or ethanol is added, the opposite perspective is assumed in Fig. 2e and $\mathrm{f}$ which reports the consumption profiles for the oxygenated fuels. From this perspective, the addition of $n$-pentane inhibits the low-temperature behavior of DME but promotes that of ethanol. The strong effect evident from the experiments upon $n$-pentane addition to DME (Fig. 2e) is also reflected in the model predictions. The measured low-temperature consumption profiles are shifted to higher temperatures by $35 \mathrm{~K}$ for PD50 and $49 \mathrm{~K}$ for PD75. Both NUIG and Polimi models overestimate the reactivity of DME in the mixture conditions, and the NUIG model presents a wider temperature shift than the Polimi model. Also, differences are noted between experiment and model in the consumption around $725 \mathrm{~K}$ as a function of $n$-pentane addition, not well reflected in the NUIC model that apparently considers only weak interaction between both fuels and thus leads to negligible deviations between the PD75 and PD50 cases. The Polimi model results in a slightly better match with the experimental consumption curve in this region. A synergistic effect between DME and $n$-pentane is observed in the experiment, detecting somewhat higher conversion of these two 

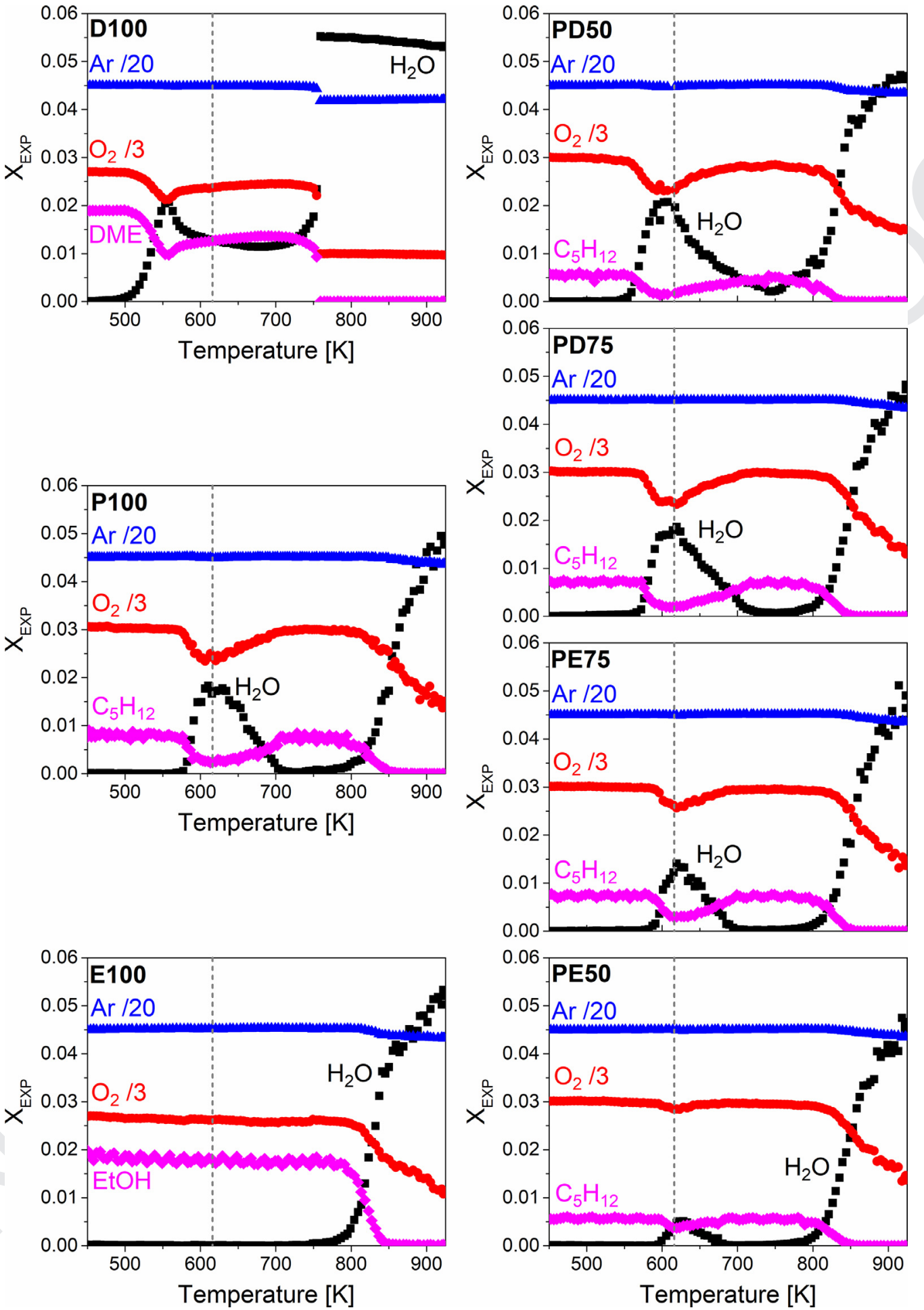

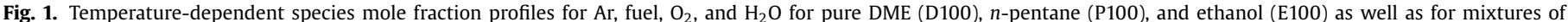

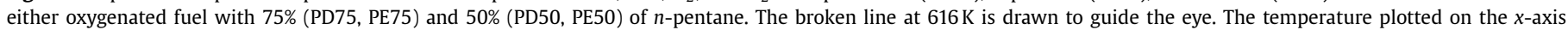
is the set temperature at the outside wall of the reactor.

active fuels in their mixtures than for each fuel individually. Trends in the two models differ in this respect.

The addition of $n$-pentane to ethanol enhances the ethanol reactivity in the low-temperature region (Fig. 2f). While inhibition of $n$-pentane consumption in this regime was already visible upon $50 \%$ ethanol addition (PE50, Fig. 2b,d), ethanol conversion in the PE50 mixture is negligible within the experimental uncertainty (therefore not included in Fig. 2f). A strong promotion tendency of $n$-pentane is seen for the PE75 mixture that shows a maxi- 391 mum low-temperature ethanol conversion of 35\%. One reason why 392 the ethanol mole fraction could decrease would be a dilution ef- 393 fect by $n$-pentane; the total moles of the reacting gas can ex- 394 pand due to the oxidation of $n$-pentane, leading to a reduction of 395 the ethanol mole fraction. To confirm the reaction of ethanol near 396 $650 \mathrm{~K}$, the result of a simulation with an assumed non-reactive 397 ethanol species is provided in Fig. S13 in SM2 that shows the di- 398 


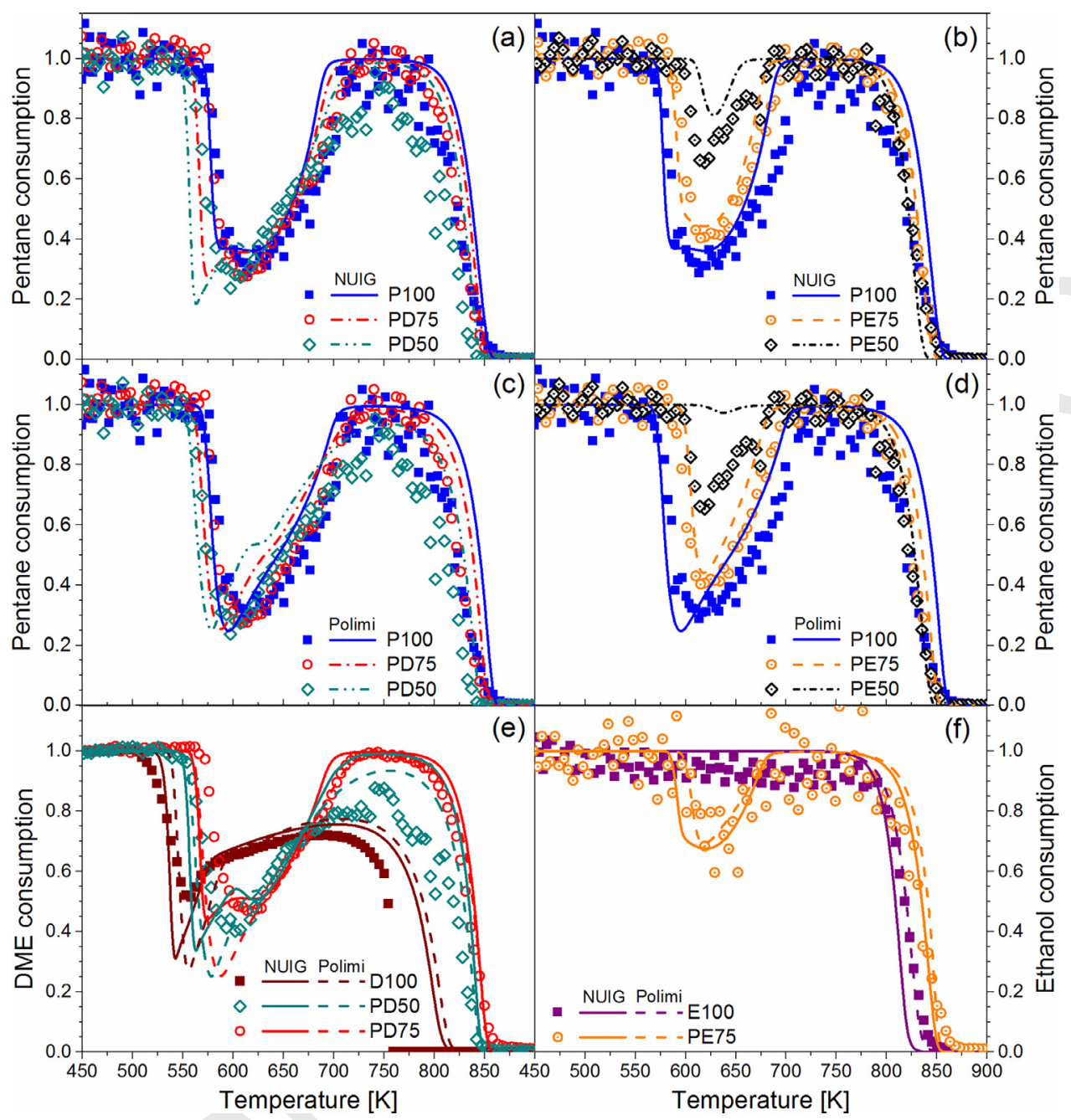

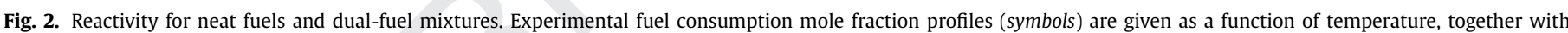

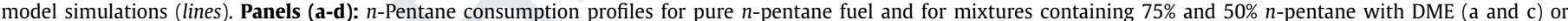

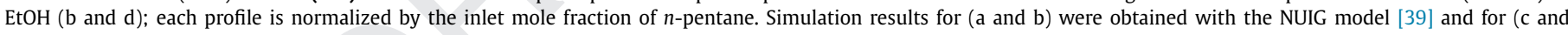

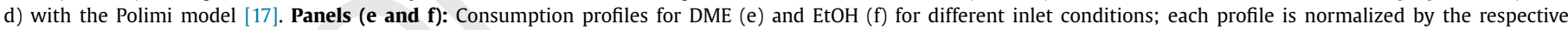

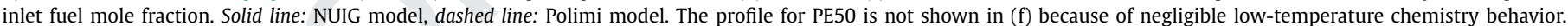

lution effect to be negligible compared to the chemical reaction. The experimental observations for $n$-pentane addition to ethanol are reasonably well predicted by both models (Fig. $2 \mathrm{f}$ ).

For a deeper understanding of the low-temperature reaction behavior of the fuel mixtures in consideration of the detailed reactions of the individual components, intermediate species formation along the fuel decomposition and oxidation reaction pathways will be presented with a focus on the experimental data, including discussion of simulation trends with the NUIG model.

\subsection{Intermediate species formation}

In the following, we will discuss the formation of key intermediate species observed in the low-temperature oxidation of the dual-fuel mixtures in view of the reaction pathways of the individual fuel components. Although the general structure of these LTC pathways is quite well known, schematic diagrams for the fuelspecific reactions in this study are presented for $n$-pentane in Fig. 3 and for the two oxygenated fuels in Fig. 4. They are intended to facilitate identification of intermediate species discussed in the text by their mass and molecular structure (compare also Table S1 in SM2) as well as by an assigned code number.
The following discussion is organized along the reaction pathways of $n$-pentane and will present the experimentally observed species profiles for this base fuel and the dual-fuel mixtures regarding important classes of low-temperature intermediates and changes upon DME and ethanol addition. Simulation results with the NUIG model are included for orientation.

Starting with the fuel $n$-pentane (RH, P1), H-abstraction forms the fuel radicals ( $R, P 2$ ) and the subsequent first oxygen addition yields pentylperoxy radicals (ROO, P3), not detectable in the present experiment, however. ROO can either form hydroperoxypentanes (P4) by $\mathrm{H}$-addition or alkenes (P5) by $\mathrm{HO}_{2}$-elimination or isomerize to $\mathrm{QOOH}$ radicals (P6). Along the reaction progress, the first stable, and thus detectable species are hydroperoxypentanes (P4) and alkenes (P5), discussed in Section 3.2.1. After isomerization of ROO (P3) $\leftrightarrow$ QOOH (P6), a second $\mathrm{O}_{2}$-addition step can occur leading to $\mathrm{O}_{2} \mathrm{QOOH}$ (P7) species. By OH-elimination the ketohydroperoxide (KHP, P8) is formed, which is the next stable and detectable intermediate, presented in Section 3.2.2, with consideration also of the ketohydroperoxide in the DME oxidation, hydroperoxymethyl formate (HPMF, D8). In Section 3.2.3, selected small oxygenated intermediates are provided including hydroperoxyalkanes, acids, and carbonyl compounds, accessible through further decomposition of the ketohydroperoxide, 


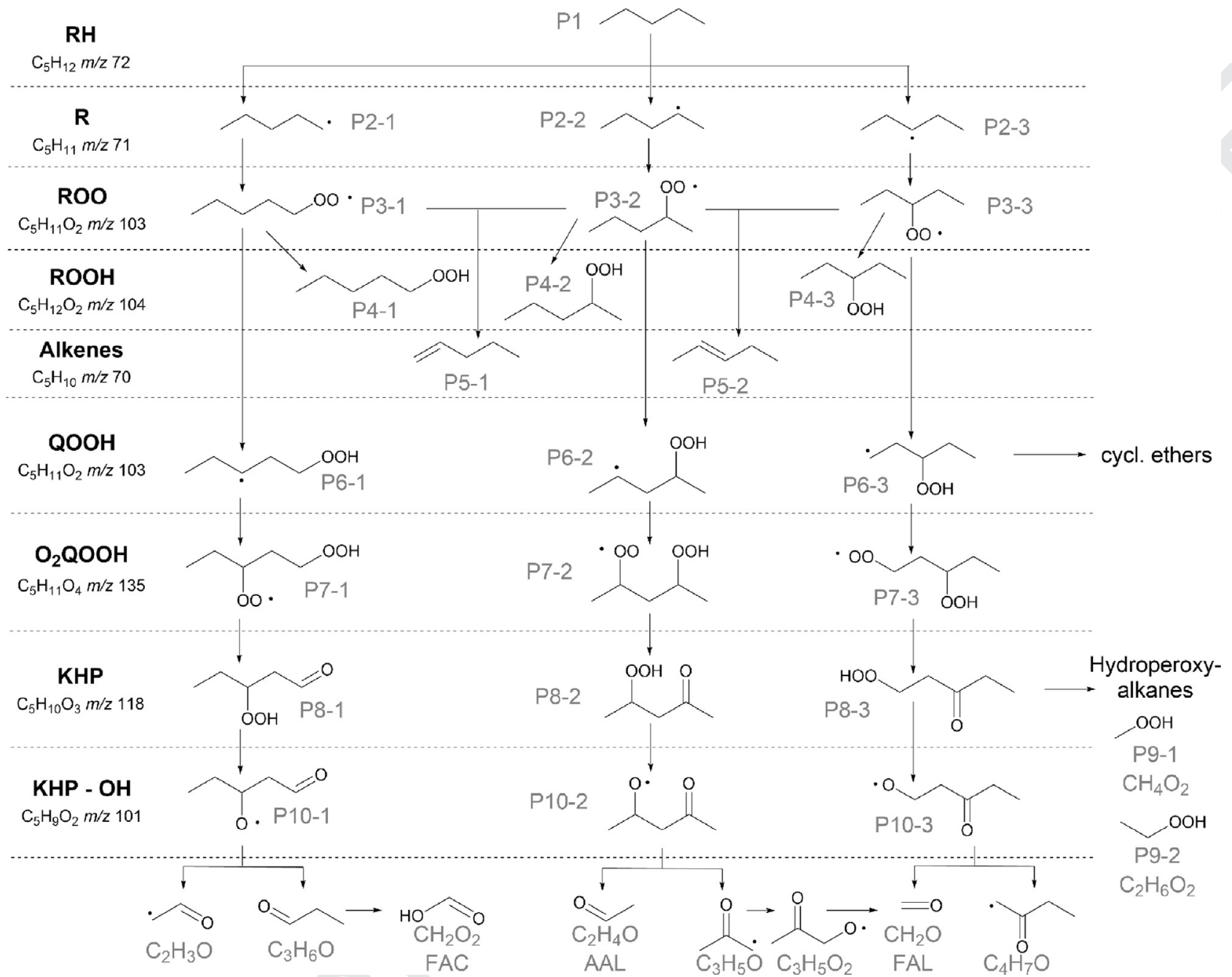

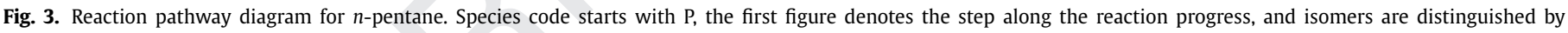
the second figure (e.g., P2-3 identifies one of the three isomers of the fuel radical in the n-pentane oxidation). FAC: formic acid, AAL: acetaldehyde, FAL: formaldehyde.

and Section 3.2.4 reports information on some further detected intermediates.

\subsubsection{Hydroperoxypentanes (P4) and pentenes (P5)}

3.2.1.1. Hydroperoxypentanes $\left(\mathrm{C}_{5} \mathrm{H}_{12} \mathrm{O}_{2}, \quad \mathrm{P} 4\right)$. Hydroperoxyalkanes are the products of $\mathrm{ROO}$ radicals via chain termination reactions, recognized as a competing channel to the ROO $\leftrightarrow \mathrm{QOOH}$ isomerization [12]. The signal of the stable species detected at a mass-to-charge ratio of $m / z=104$ with formula $\mathrm{C}_{5} \mathrm{H}_{12} \mathrm{O}_{2}$ is therefore assigned here to hydroperoxypentanes (P4), without a possibility to discriminate between the P4-1, P4-2, and P4-3 isomers in Fig. 3, however. Temperature-dependent $\mathrm{C}_{5} \mathrm{H}_{12} \mathrm{O}_{2}$ profiles for the different conditions are provided in Fig. 5. The experimental profiles present the maximum for the base fuel $n$-pentane near $585 \mathrm{~K}$ in close agreement with the start of the fuel conversion. Small temperature shifts are observed when adding DME or ethanol to n-pentane. Modeling results, however, predict more important shifts, similarly to those observed for the $n$-pentane consumption profiles in Fig. 2. Quantification of hydroperoxypentanes (P4) was not possible because of lacking electron ionization cross sections, but the relative trends, namely higher conversion of $\mathrm{C}_{5} \mathrm{H}_{12} \rightarrow \mathrm{C}_{5} \mathrm{H}_{12} \mathrm{O}_{2}$ in the mixtures, are evident from the observed signal intensities, normalized to the inlet $n$-pentane mole fraction. As an indication for the probable concentration range, a mole fraction of about $3 \times 10^{-5}$ has been observed by Rodriguez et al.
[40] for the sum of hydroperoxypentanes in pure $n$-pentane oxidation under their lean JSR conditions. Hydroperoxypentane isomers (P4) are formed via the reaction of hydroperoxypentyl radicals $\left(\mathrm{C}_{5} \mathrm{H}_{11} \mathrm{O}_{2}, \mathrm{ROO}, \mathbf{P 3}\right)$ and $\mathrm{HO}_{2}$. Thus, the formation of hydroperoxypentane (P4) is determined by the efficiency of the pentyl (P2) production in the reacting system. DME oxidation provides an enhanced amount of $\mathrm{OH}$ radicals already at lower temperatures, shifting hydroperoxypentane (P4) formation to lower temperatures and slightly increasing the amount. In contrast, ethanol reduces the production of hydroperoxypentanes (P4) and increases their formation temperature slightly. Particularly for the PE50 mixture, the signal is too weak to be detected in the experiment, thus only the modeling result is provided in Fig. 5. The NUIG model predictions show a slight tendency to overestimate the intensity of the influence of the oxygenated additive.

3.2.1.2. Pentenes $\left(\mathrm{C}_{5} \mathrm{H}_{10}, \mathrm{P5}\right)$. Temperature-dependent profiles for 481 $\mathrm{C}_{5} \mathrm{H}_{10}$ (P5) are given in Fig. 6; the mole fraction represents the 482 sum of 1-pentene and 2-pentene, with the $\mathrm{C}_{5} \mathrm{H}_{10}$ signal cali- 483 brated as 1-pentene (with calibration based on 2-pentene, the total 484 mole fraction would be $4.9 \%$ higher). The profiles reveal both low- 485 temperature reactions as well as high-temperature formation from 486 the fuel radicals (R, P2). Temperature shifts in both regimes are 487 negligible for DME addition and minor upon ethanol addition, a 488 trend that is also well captured by the model. Mixtures containing 489 


\section{EtOH}

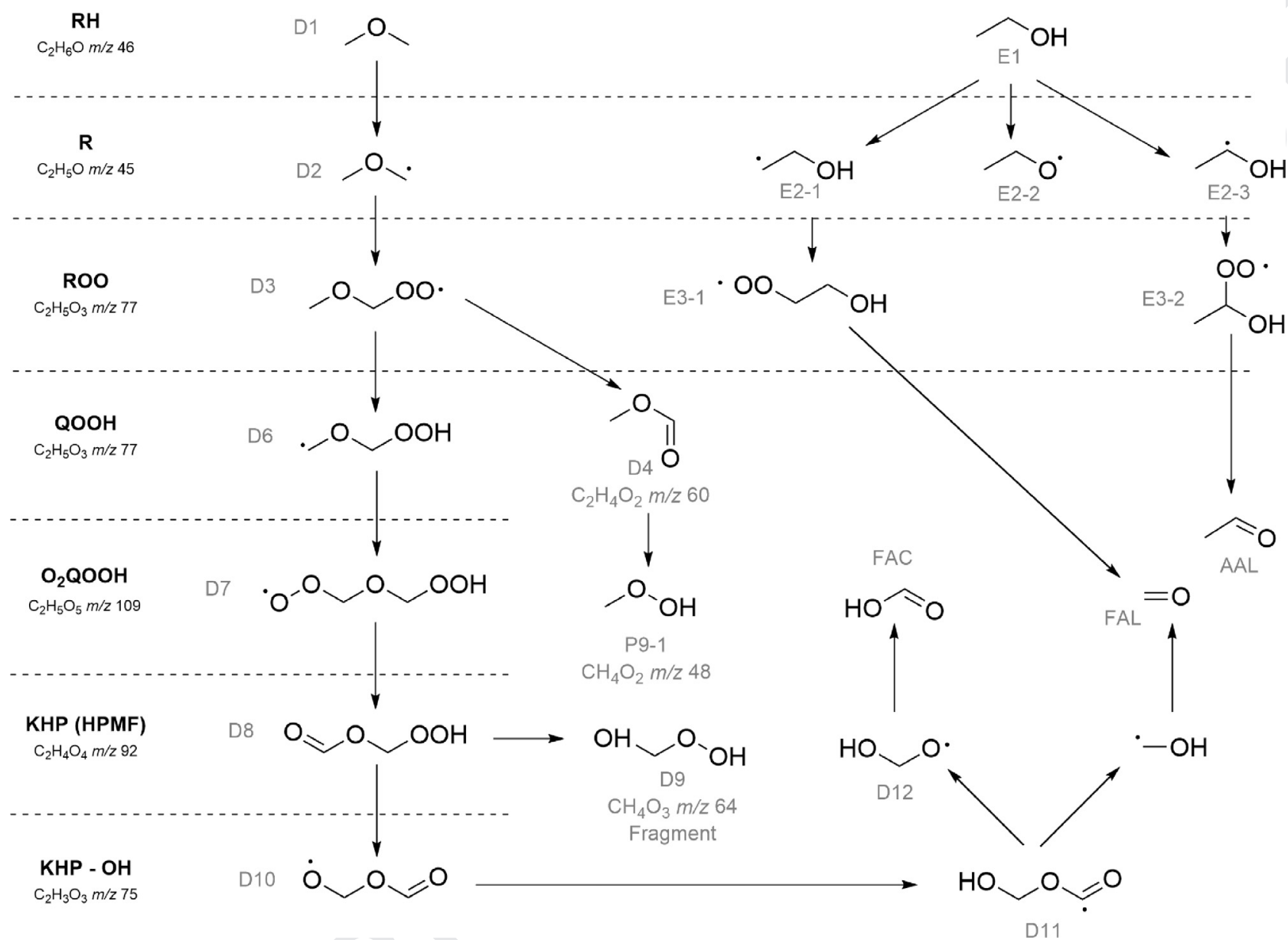

Fig. 4. Reaction pathway diagram for DME and ethanol. Species codes follow the same rules as in Fig. 3. FAC: formic acid, AAL: acetaldehyde, FAL: formaldehyde.

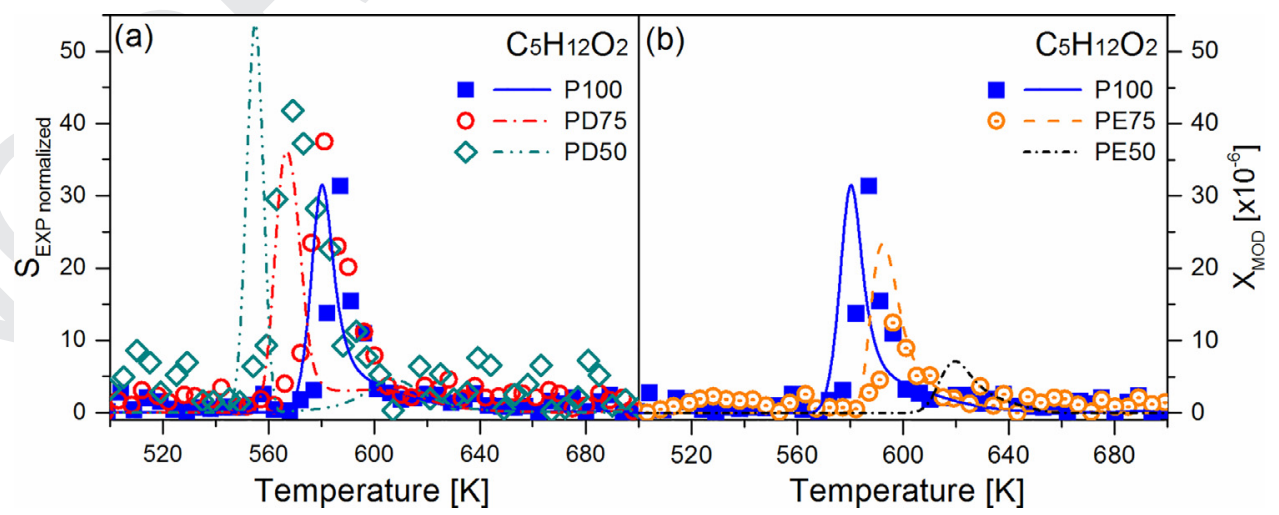

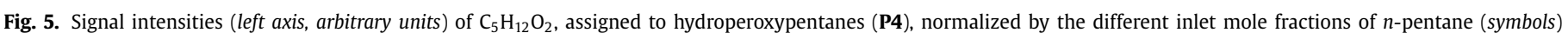

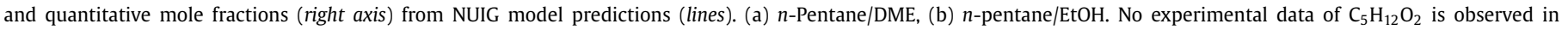
PE50 due to its low concentration, thus only the modeling result is provided.

75\% n-pentane (PD75 and PE75) present similar pentene maxima to that in pure $n$-pentane (P100) oxidation, and reduction effects are only visible for the 50:50 mixtures (PD50 und PE50). Simulation results have been divided by a factor of 2 to fit the scale in Fig. 6 since the model over-predicts the mole fractions in all cases. For pure $n$-pentane oxidation, Bugler et al. [39] also show a tendency to over-predict especially 2-pentene concentrations under lean conditions at $\phi=0.5$ and $1 \mathrm{~atm}$.
3.2.2. Ketohydroperoxides (P8, D8)

3.2.2.1. Pentane ketohydroperoxide $\left(\mathrm{C}_{5} \mathrm{H}_{10} \mathrm{O}_{3}, \mathrm{P} 8\right)$. Figure 7 presents the signal intensity for $\mathrm{C}_{5} \mathrm{H}_{10} \mathrm{O}_{3}$ (P8), normalized by the different $n$-pentane inlet conditions. Note again that all profiles should be identical because of this normalization if no mixture effects would occur. The observed signal can be ascribed to the sum of $\mathrm{C}_{5}$-ketohydroperoxide (P8), the three isomers of which have been identified by Rodriguez et al. [40]; from their SVUV-PIMS 


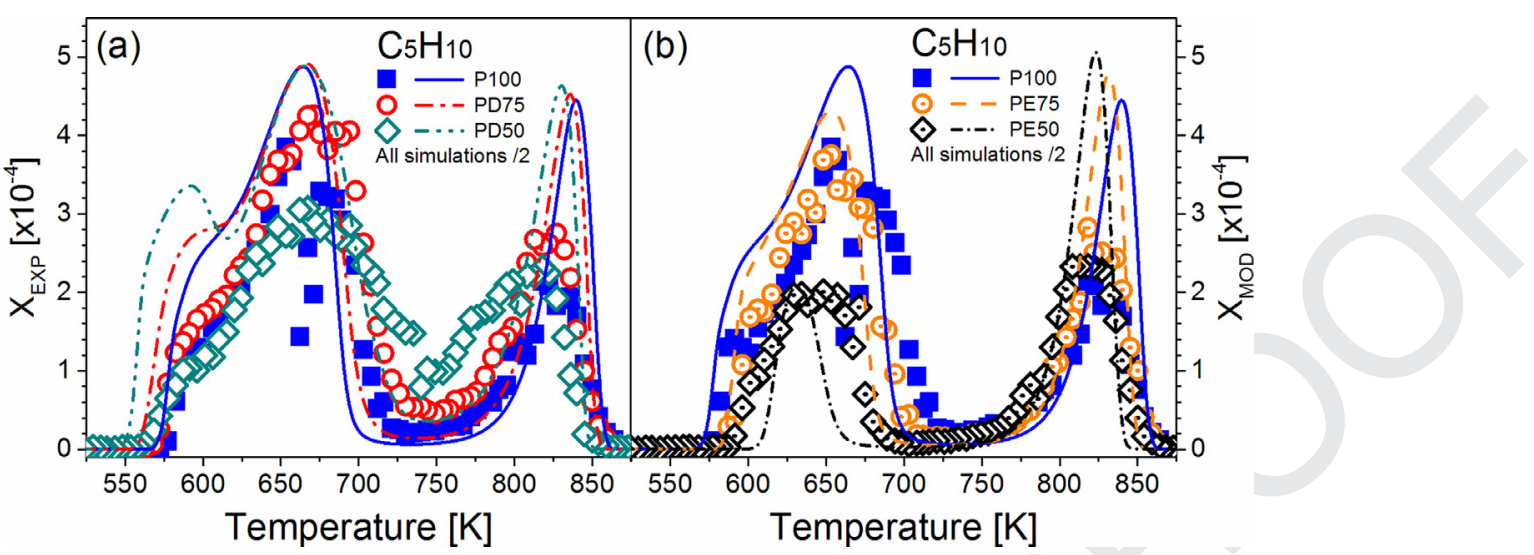

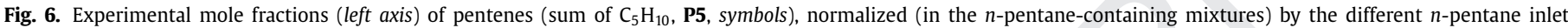

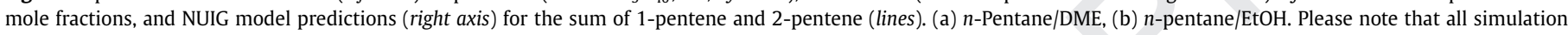
results have been divided by a factor of 2 .

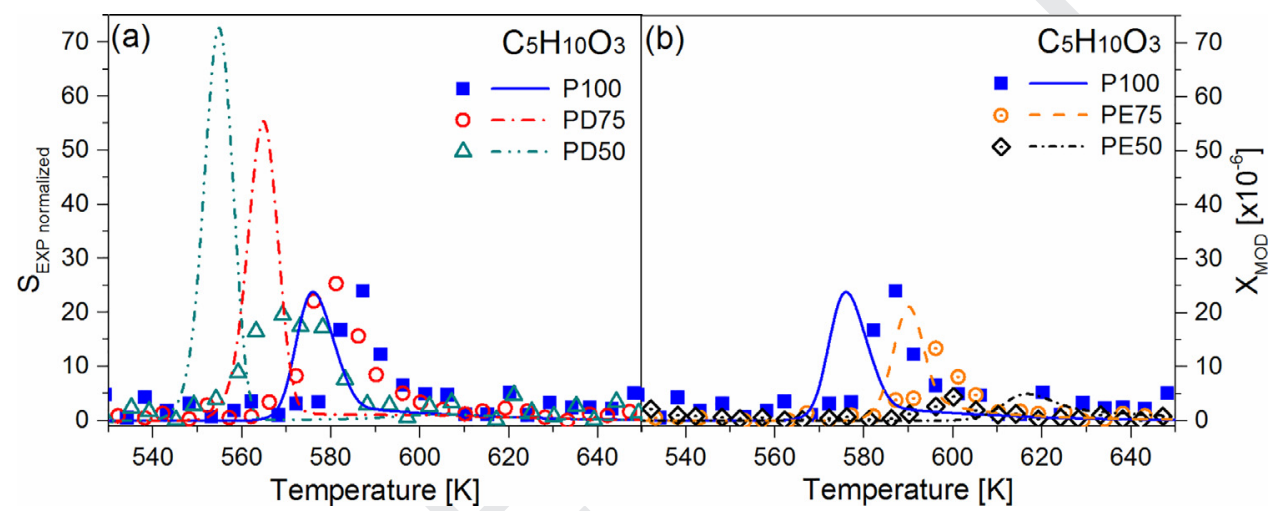

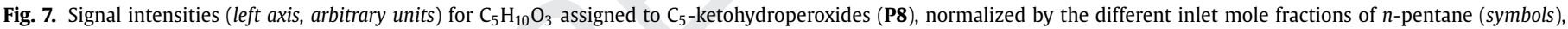
and quantitative mole fractions (right axis) from NUIG model prediction (lines). (a) n-Pentane/DME, (b) $n$-pentane/EtOH.

study they reported a somewhat preferential formation of 3hydroperoxy-pentanal (P8-1) and 1-hydroperoxy-3-pentanone (P83) over that of 2-hydroperoxy-4-pentanone (P8-2), which is kinetically favored, however, and provided mole fraction values of the order of $10^{-5}$ for the sum of the $C_{5}$-ketohydroperoxides for pure $n$ pentane oxidation under lean JSR conditions. Quantification is not possible here because electron ionization cross sections are lacking. The addition of DME (Fig. 7a) reduces the formation temperature, in agreement with the observed tendencies for n-pentane consumption and hydroperoxypentane formation (see above). The model represents the relative profile shape reasonably well for the pure n-pentane (P100) case. For the mixtures investigated here, the model overestimates the influence of DME. The reason may be lacking low-temperature-related reactions of the mixtures, as e.g., $\mathrm{RO}_{2}+\mathrm{R}^{\prime} \mathrm{O}_{2} \rightarrow \mathrm{RO}+\mathrm{R}^{\prime} \mathrm{O}+\mathrm{O}_{2}$ and $\mathrm{H}$-abstraction of the $\mathrm{RO}_{2}$ species of both fuels. With the addition of ethanol, the reactivity of the system is significantly reduced (Fig. 7b), and the profiles for the $n$-pentane/ethanol blends are shifted to higher temperature. The maximum signals decrease, in agreement with the lower consumption of $n$-pentane in Fig. $2 \mathrm{~b}$. The NUIG model can reproduce the tendencies for different conditions reasonably well, with the somewhat larger differences in the NTC region that were already evident in the fuel consumption profiles (Fig. 2b). For all five conditions, the experimental peak positions agree well with those for the hydroperoxypentanes (P4), as might be expected from the close relation of these species along the reaction pathway (Fig. 3), and those from the model again exhibit a larger spread in temperature.
3.2.2.2. DME ketohydroperoxide $\left(\mathrm{C}_{2} \mathrm{H}_{4} \mathrm{O}_{4}, \mathrm{HPMF}, \mathrm{D} 8\right)$. The general formation path of the ketohydroperoxide of DME proceeds similar to that of the pentane ketohydroperoxide (compare Fig. 4). In their experiments focused on low-temperature oxidation of DME in a JSR, Moshammer et al. [53,54] have identified the signal at $m / z=92$ corresponding to the sum formula of $\mathrm{C}_{2} \mathrm{H}_{4} \mathrm{O}_{4}$ as hydroperoxymethyl formate (HPMF, D8). In the present work, HPMF (D8) was only detected for pure DME conditions due to its significant fragmentation and correspondingly, low signal. $\mathrm{CH}_{4} \mathrm{O}_{3}$ at $m / z=64$ was confirmed by Moshammer et al. [53] to be a dominant fragment of HPMF (D8) by CO loss. They also performed theoretical calculations and assigned its structure as hydroxymethyl hydroperoxide $\left(\mathrm{HOOCH}_{2} \mathrm{OH}\right.$, D9), clarifying earlier results of Wang et al. [41], who had also reported strong signals at this mass but assumed the species to be either hydroxymethyl hydroperoxide (D9) or trihydroxymethane. For the PD75 and PD50 mixtures, we thus consider the signal at $m / z=64$ to be representative of HPMF (D8) in light of the results of [53]. Figure 8 reports the results for $m / z=92$ (HPMF, D8) in the pure DME case (see insert top left) and $m / z=64\left(\mathrm{CH}_{4} \mathrm{O}_{3}\right.$, D9 $)$ for pure DME and the PD75 and PD50 mixtures. The temperatures of the maxima for both signals agree, supporting the assumption that the signal at $m / z=64$ can be used as an indicator for HPMF.

With the addition of a large amount of $n$-pentane, the concentration of HPMF (D8) decreases significantly, e.g., a reduction of $90 \%$ for PD50 which can be partly due to diluting and chemical effects. Further reasons can include the shift toward higher temperatures that could enhance the decomposition of such labile 


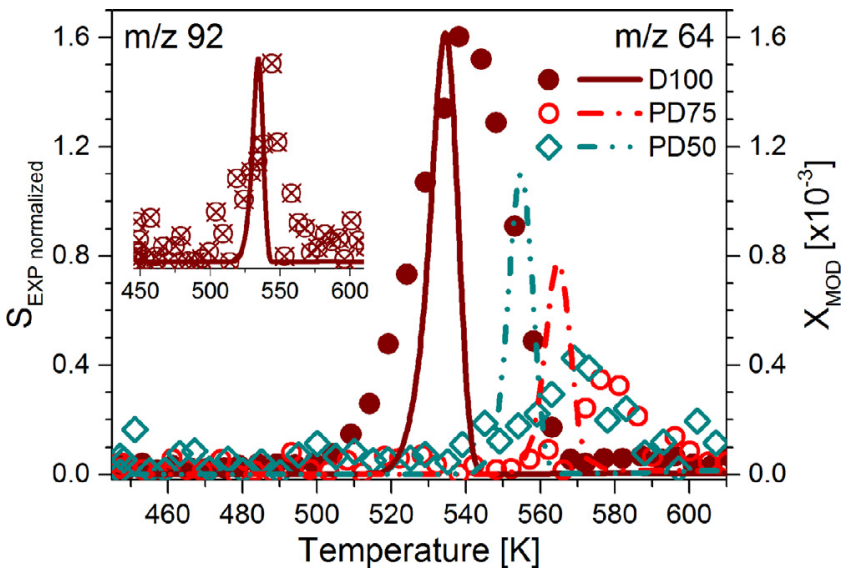

Fig. 8. Signal intensities (symbols, left axis, arbitrary units) of $m / z=64\left(\mathrm{CH}_{4} \mathrm{O}_{3}\right.$, D9) and (insert top left) of $m / z=92$ (HPMF, D8) for D100, together with quantitative mole fractions from NUIG model predictions for HPMF (lines, right axis). For D100 and $m / z=64$, both measured and modeled results are divided by a factor of 5. Profiles have been normalized by the different inlet mole fractions for DME.

species. Higher temperatures would also favor the reverse reaction of $\mathrm{R}+\mathrm{O}_{2}$, leading to a lower formation of ketohydroperoxide species and ultimately to reduced $\mathrm{OH}$ concentrations involved in forming fuel radicals. Nevertheless, the change seems more significant than that for the $\mathrm{C}_{5}$-ketohydroperoxides (P8) in Fig. 7, and it may reveal information about the competition of the DME radical $\left(\mathrm{CH}_{3} \mathrm{OCH}_{2}\right.$, D2) with the pentyl radical (P2) in the combination with $\mathrm{O}_{2}$ molecules. Concerning the profile shapes, the NUIG model (D8) predicts a narrower temperature distribution of HPMF than the experiment for all conditions, with a width of only $\sim 20 \mathrm{~K}$ versus $\sim 50 \mathrm{~K}$ in the experiment, and it also provides smaller temperature shifts than the experiments with increasing $n$-pentane addition.

\subsubsection{Selected small oxygenated intermediates}

3.2.3.1. Hydroperoxymethane $\left(\mathrm{CH}_{4} \mathrm{O}_{2}, \mathrm{P9}-1\right)$ and hydroperoxyethane $\left(\mathrm{C}_{2} \mathrm{H}_{6} \mathrm{O}_{2}, \mathrm{P9}-2\right)$. Unlike hydroperoxypentanes (P4) that were discussed before, smaller hydroperoxyalkanes are secondary oxidation products. Within the detection limit of the experiment of a few ppm, no quantifiable signals could be observed for hydroperoxybutane $\left(\mathrm{C}_{4} \mathrm{H}_{10} \mathrm{O}_{2}\right)$ and hydroperoxypropane $\left(\mathrm{C}_{3} \mathrm{H}_{8} \mathrm{O}_{2}\right)$. However, the smaller species hydroperoxymethane $\left(\mathrm{CH}_{4} \mathrm{O}_{2}, \mathbf{P 9 - 1}\right)$ and hydroperoxyethane $\left(\mathrm{C}_{2} \mathrm{H}_{6} \mathrm{O}_{2}\right.$, P9-2) could be found. Methyl and ethyl radicals are derived from the decomposition of $\mathrm{C}_{5}$-ketohydroperoxides (P8) and pentylperoxy radicals (ROO, P3), and their reactions with $\mathrm{O}_{2}$ or $\mathrm{HO}_{2}$ can lead to the formation of these smaller hydroperoxyalkanes. The profiles of $\mathrm{CH}_{4} \mathrm{O}_{2}$ (P9-1) and $\mathrm{C}_{2} \mathrm{H}_{6} \mathrm{O}_{2}$ (P9-2) in Fig. 9 are normalized (in the $n$-pentane-containing mixtures) by the inlet mole fractions of $n$-pentane, and for the pure fuels, P100 shows higher conversion to these small hydroperoxyalkanes (P9) than DME.

Since doping with DME promotes the reactivity of the system and consequently, the formation of pentyl radicals ( R, P2) and of typical intermediates derived from the fuel decomposition, it also enhances the formation of the hydroperoxyalkanes in Fig. 9a and $c$ in the PD75 mixture. No significant further increase is observed with increased DME content for PD50, however. This behavior is different in the model for both, hydroperoxymethane (Fig. 9a and b) and hydroperoxyethane (Fig. 9c and d), especially for the formation of the latter in PD50. In the oxidation of DME, hydroperoxymethane (P9-1) is proposed to be formed along a sequence from the $\mathrm{CH}_{3} \mathrm{OCH}_{2} \mathrm{OO}$ radical (the ROO of DME, D3) via methyl formate (D4) and methyl radicals [54,69]. For pure DME (D100), hydroperoxymethane (P9-1) is indeed experimentally observed as shown in Fig. 9a, but the NUIG model predicts only insignificant amounts. Similar observations were noted by Moshammer et al [54], who report a mole fraction for hydroperoxymethane of the order of $10^{-5}$ and point out large discrepancies between their DME JSR experiment and several models including the NUIG DME mech-

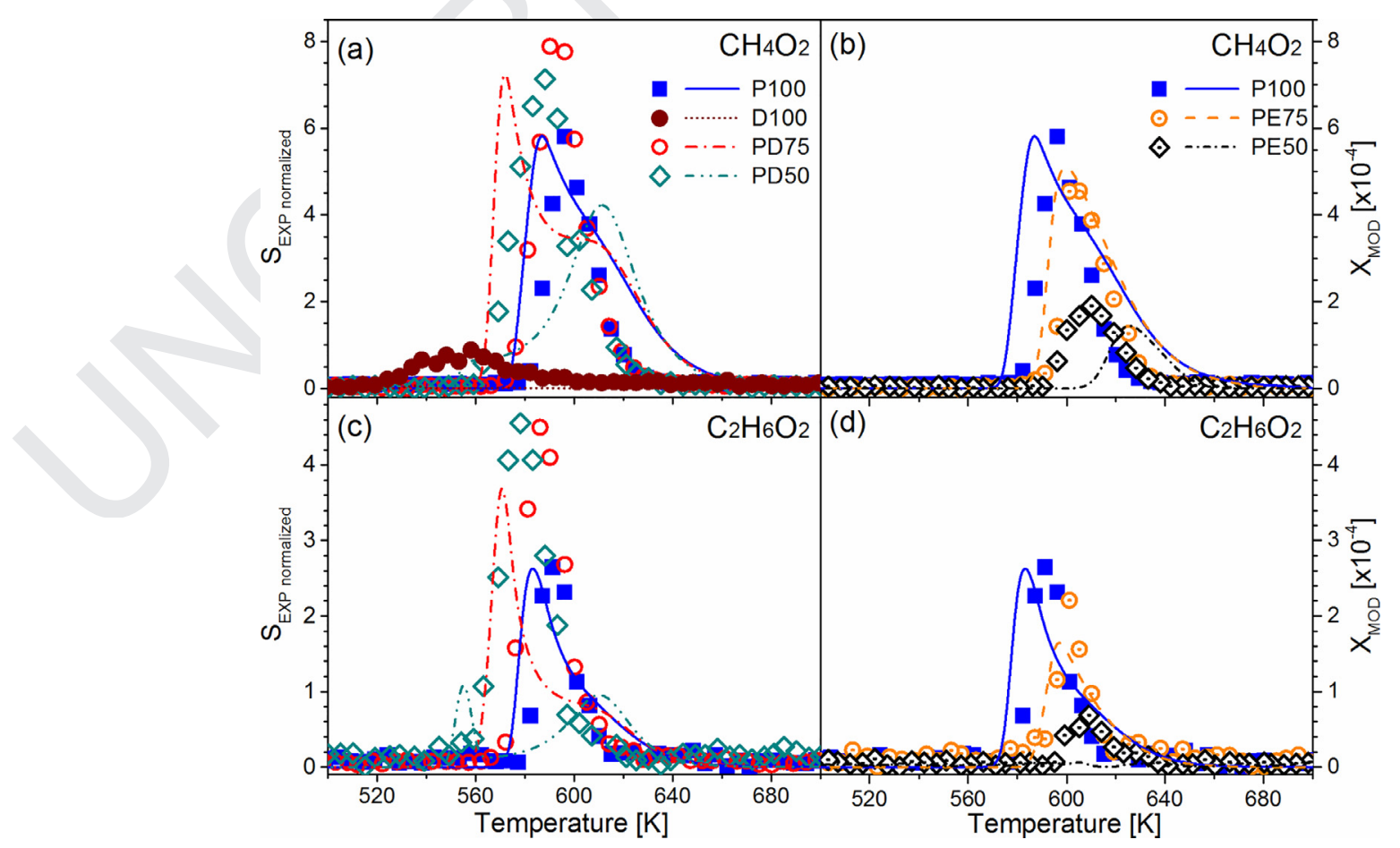

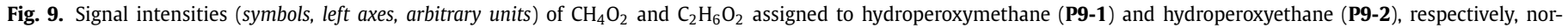

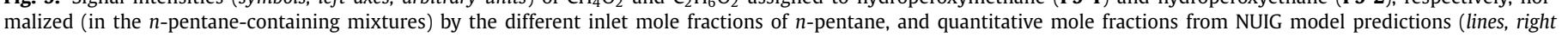
axes). (a and c) n-Pentane/DME, (b and d) n-pentane/EtOH. 


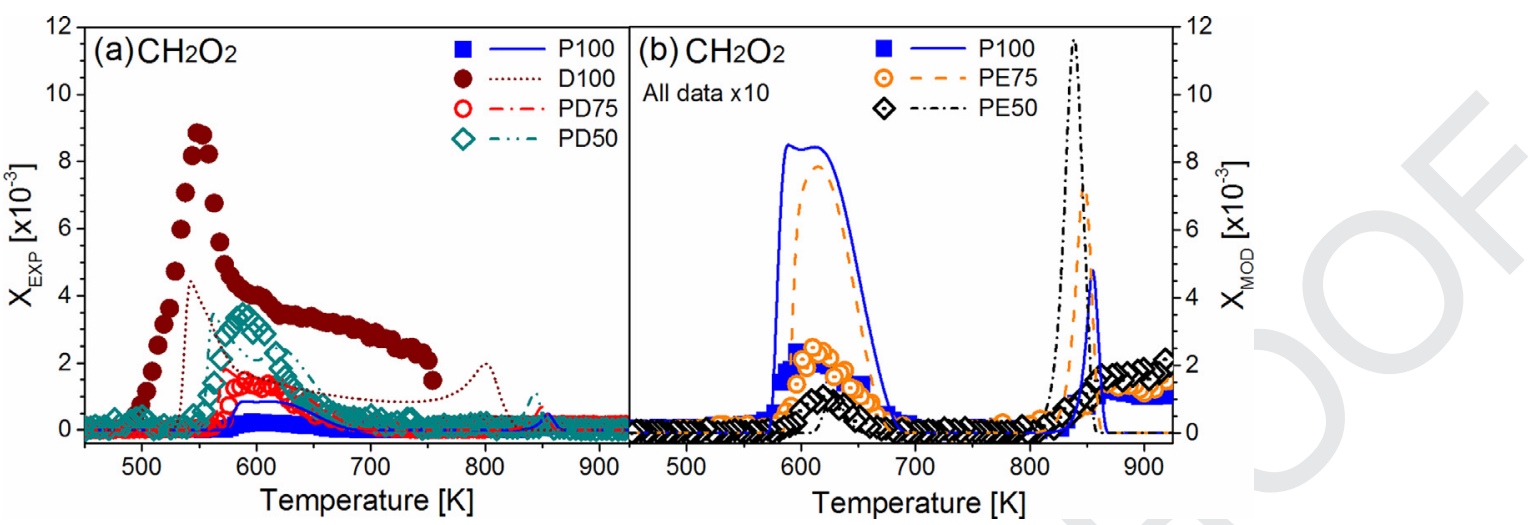

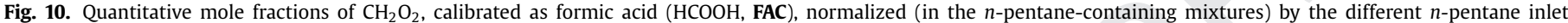
mole fractions. Symbols: experiment (left axes); lines: NUIG model predictions (right axes). (a) n-Pentane/DME, (b) n-pentane/EtOH.

anism [7]. Ethanol can form neither of these hydroperoxyalkanes in its low-temperature reactions, so that in mixtures of $n$-pentane and ethanol they must be produced only from $n$-pentane. Their formation tendencies in P100, PE75, and PE50 (Fig. 9b and d) are similar to those of the hydroperoxypentanes (P4) (see Fig. 5b). The shift with ethanol to higher temperature is expected because of the decrease of the system in reactivity. The wider spread of the peak temperatures in the modeling results is similar to that shown before for the $\mathrm{C}_{5}$-ketohydroperoxides (P8). The NUIG model represents the observed tendencies for these mixtures reasonably well.

3.2.3.2. Formic acid (FAC). Acids are important intermediates in the fuel oxidation process and lead to the formation of $\mathrm{CO}, \mathrm{CO}_{2}$, and esters. For the mixtures of $n$-pentane and DME, pentanoic, acetic, and formic acid are the most favorable products. Possible acid mass peaks, at $m / z=102,60$, and 46 respectively, were detected in this work by EI-MBMS. However, in their investigation of $n$-pentane oxidation with SVUV-PIMS, Rodriguez et al. [40] identified the peak of $m / z=102$ as pentenylhydroperoxide, and their PIE curve did not indicate a slope at the ionization energy of pentanoic acid. The species of $m / z=60$ was identified as acetic acid by GC in the $n$ pentane oxidation study of Bugler et al. [39]. Here, we would need to consider not only acetic acid for $m / z=60$ but also methyl formate, since it dominates in the oxidation of DME [51]. With the used electron ionization, however, isomer identification was not possible. The signal at $m / z=46\left(\mathrm{CH}_{2} \mathrm{O}_{2}\right)$ is likely to be formic acid (FAC) as there are no other reasonable isomers, and is therefore calibrated as formic acid in this experiment. It is a typical DMEderived intermediate. $n$-Pentane also forms formic acid (FAC), but not in a similar amount as DME. Thus, FAC is selected as a typical species here to represent the interaction of $n$-pentane and DME. Figure 10a shows the experimental results for pure $n$-pentane, DME, and their mixtures, together with model simulations, while the complementary mixtures with ethanol, for which no significant interaction is noted, are presented in Fig. 10b.

Large temperature shifts are seen along the replacement of $n$ pentane with DME that are quite well matched by the model and correspond approximately to the consumption maxima in Fig. 2. Trends for the mixtures in the low-temperature region are quite well captured by the NUIG model that over-predicts FAC for P100, however, and under-predicts it for D100. This could be explained by the lacking importance of a reaction producing formic acid as suggested by Wang et al. [70]. They showed that the isomerization reaction of $\mathrm{OCH}_{2} \mathrm{OCHO} \rightarrow \mathrm{HOCH}_{2} \mathrm{OCO}$ is predicted to be more dominant in most models than its reaction to form formic acid $\left(\mathrm{OCH}_{2} \mathrm{OCHO} \rightarrow \mathrm{HCOOH}+\mathrm{HCO}\right)$ which has; however, a much lower energy barrier and should therefore be more dominant (see Fig. 3 of Ref. [70]). For the $n$-pentane/DME mixtures, the NUIG model re-

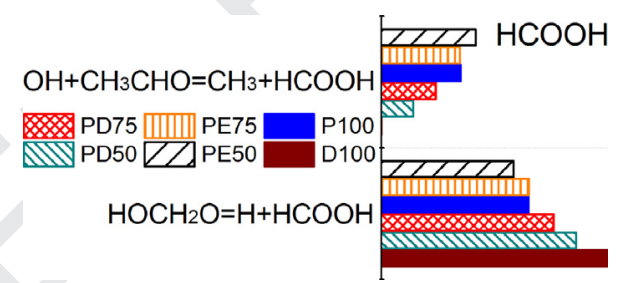

Fig. 11. Rate of production analysis of formic acid ( $\mathrm{HCOOH})$ for different inlet conditions modeled by the NUIG model at the temperatures of the respective maximum mole fraction $( \pm 5 \mathrm{~K})$ in the NTC zone.

veals two formation pathways of formic acid to yield major contributions as shown in the rate of production (ROP) analysis in Fig. 11, where the reaction suggested in Ref. [70] is not considered.

From the ROP in Fig. 11 it can be seen that the pathway involving acetaldehyde $\left(\mathrm{CH}_{3} \mathrm{CHO}, \mathbf{A A L}\right)$ is important in the $n$-pentane oxidation, while the $\mathrm{HOCH}_{2} \mathrm{O}$ radical (D12) channel contributes for both fuels, but to a larger extent for DME oxidation. Over this channel, FAC is formed via the decomposition of HPMF (D8) for D100 (see Fig. 4), or the combination of $\mathrm{OH}$ and $\mathrm{CH}_{2} \mathrm{O}$ via the intermediate radical of $\mathrm{HOCH}_{2} \mathrm{O}$ for P100 (see Fig. 3). The formaldehyde pathway becomes more important with the addition of DME. However, the rate constant of this channel estimated in the NUIG model is much faster than that from the theoretical investigation of Xu et al. [71], and its influence might thus be overestimated.

3.2.3.3. Carbonyl compounds. Formaldehyde (FAL), acetaldehyde (AAL), and butanone are important intermediates in $n$-pentane oxidation [39]. AAL is mainly formed via the decomposition of 2hydroperoxy-4-pentanone (P8-2), which is, however, not the major ketohydroperoxide isomer in the $n$-pentane oxidation according to Rodriguez et al. [40], who measured only P8-1 and P8-3 in their experiment. However, P8-2 is quite important in the formation of methyl radicals and impacts the formation of hydroperoxymethane (P9-1), formaldehyde (FAL) and even $\mathrm{OH}$ radicals via its subsequent reactions. The mole fractions of acetaldehyde and formaldehyde, normalized (in the $n$-pentane-containing mixtures) by the inlet mole fraction of $n$-pentane, are given in Fig. 12 ; as stated before, changes observed are thus due to interactive effects in the mixtures.

As seen in Fig. 12a, the AAL mole fraction is not changed significantly upon blending with 25\% DME, but it is notably reduced with 50\% DME, while the model predicts a constant AAL mole fraction. With increasing ethanol addition (Fig. 12b), the pathway forming acetaldehyde from ethanol (compare Fig. 4) gains importance, as also seen in the ROP analysis in Fig. 13. Ethanol is ac- 


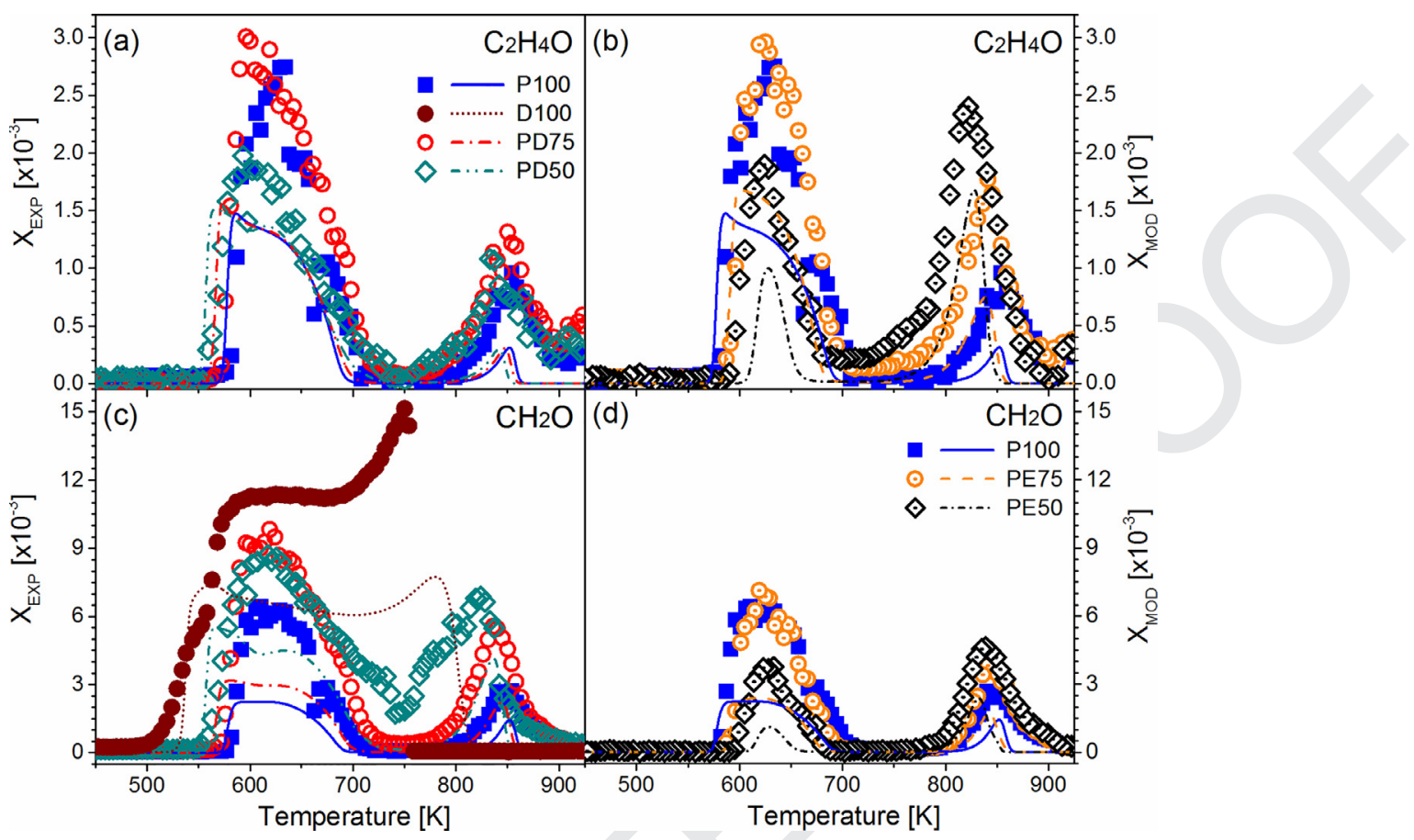

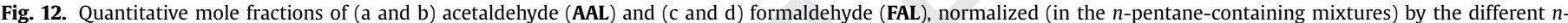

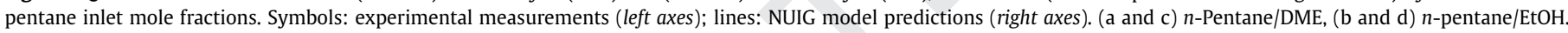

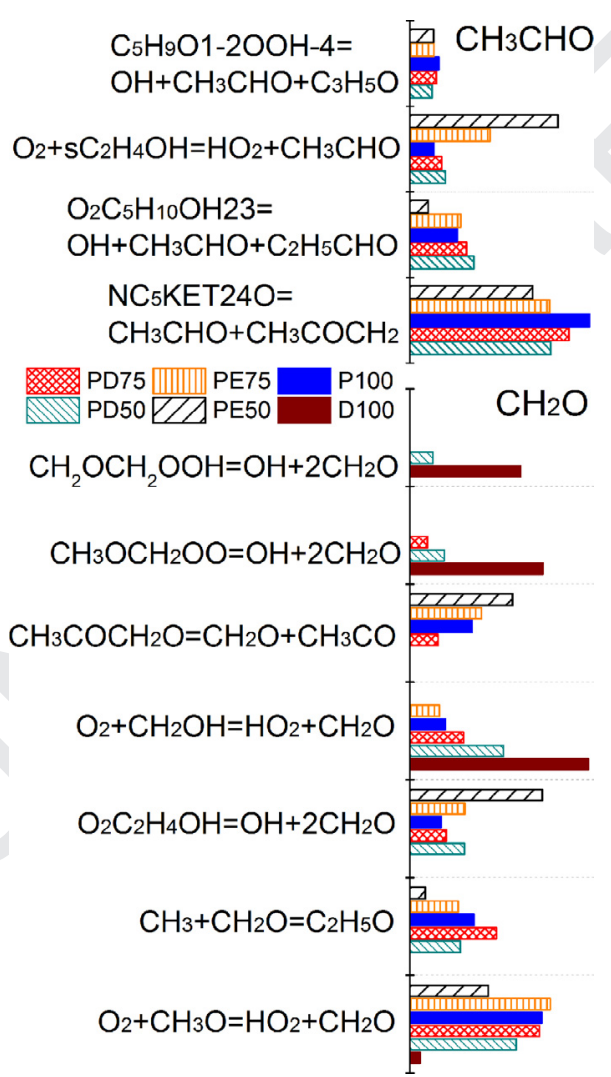

Fig. 13. Contributions of the main pathways in the formation of acetaldehyde $\left(\mathrm{CH}_{3} \mathrm{CHO}, \mathbf{A A L}\right)$ and formaldehyde $\left(\mathrm{CH}_{2} \mathrm{O}, \mathbf{F A L}\right)$ for the different inlet conditions. The results were obtained with the NUIG model at the respective maximum AAL and FAL mole fractions $( \pm 5 \mathrm{~K})$ in the NTC zone. Abbreviations: $\mathrm{C}_{5} \mathrm{H}_{9} \mathrm{O} 1-2 \mathrm{OOH}-4$ is 2hydroperoxy-4-methyltetrahydrofuran, $\mathrm{O}_{2} \mathrm{C}_{5} \mathrm{H}_{10} \mathrm{OH} 23$ the pentan-3-ol-2-peroxy radical, $\mathrm{NC}_{5} \mathrm{KET} 24 \mathrm{O}(\mathbf{P 1 0}-2)$ the 2-pentanoxide-4-one radical, and $\mathrm{sC}_{2} \mathrm{H}_{4} \mathrm{OH}(\mathbf{E 2 - 3})$ the $\alpha$-ethanol radical. (Compare also nomenclature and structures in Table S1 in SM2). tivated by $\mathrm{OH}$ provided by the $n$-pentane oxidation. The ethanol radical $\left(\mathrm{sC}_{2} \mathrm{H}_{4} \mathrm{OH}, \mathbf{E 2}-3\right)$ that consumes $\sim 70 \%$ of ethanol is the precursor of acetaldehyde.

Formaldehyde (FAL) as a typical oxidation intermediate is formed by different reactions for the three investigated fuels. $\mathrm{CH}_{3}$ radical reactions provide major contributions to FAL for $n$ pentane, while the decomposition of $\mathrm{CH}_{3} \mathrm{OCH}_{2} \mathrm{OO}(\mathrm{ROO}, \mathrm{D} 3)$ and $\mathrm{CH}_{2} \mathrm{OCH}_{2} \mathrm{OOH}(\mathrm{QOOH}$, D6) radicals are the main formation reactions of formaldehyde (FAL) in the oxidation of DME. For ethanol, the formation of FAL involves pathways via the methyl and the $\mathrm{O}_{2} \mathrm{C}_{2} \mathrm{H}_{4} \mathrm{OH}$ (E3-1) radicals. Figure $12 \mathrm{c}$ and $\mathrm{d}$ shows the normalized mole fractions of formaldehyde for all mixtures. Opposite tendencies are observed. With DME addition, the mole fraction increases compared to P100, but PD75 and PD50 show nearly the same amount. With the addition of ethanol, the mole fraction is similar for P100 and PE75, but lower for PE50.

The behavior of acetaldehyde (AAL) and formaldehyde (FAL) could be roughly explained by the enhanced $\mathrm{H}$-abstraction of $\mathrm{C}_{5}$ ketohydroperoxides (P8) according to the work of Ranzi et al. [17]. The common reaction pathway for the decomposition of ketohydroperoxide species is described as $0-0$ scission and subsequent $\beta$-scission. Here, this reaction sequence would lead to the formation of acetaldehyde. However, the decomposition pathway by $\mathrm{H}$-abstraction of the $\mathrm{C}_{5}$-ketohydroperoxide and subsequent $\beta$-scission proposed by Ranzi et al. [17] would lead to pentadione and ketene. These recently proposed reaction classes are not included in the NUIG kinetic model, and their implementation could lead to a better prediction of acetaldehyde especially for PD50 compared to PD75 (see Fig. 12a). The ROP analysis for acetaldehyde (AAL) in Fig. 13 shows that $\mathrm{NC}_{5} \mathrm{KET} 240(\mathbf{P 1 0}-2)$ is the main pathway, with the caveat, however, that the used model does not include the competing channels. The ROP analysis for formaldehyde (FAL) in Fig. 13 shows another important formation channel from the $\mathrm{CH}_{3} \mathrm{COCH}_{2} \mathrm{O}$ radical (via the acetonyl radical) in the blends with ethanol. It is a product of the unimolecular decomposition of 2-hydroperoxy-4-pentanone (P8-2). Because of the reduced amount of $\mathrm{OH}$ by ethanol, it reduces the gen- 


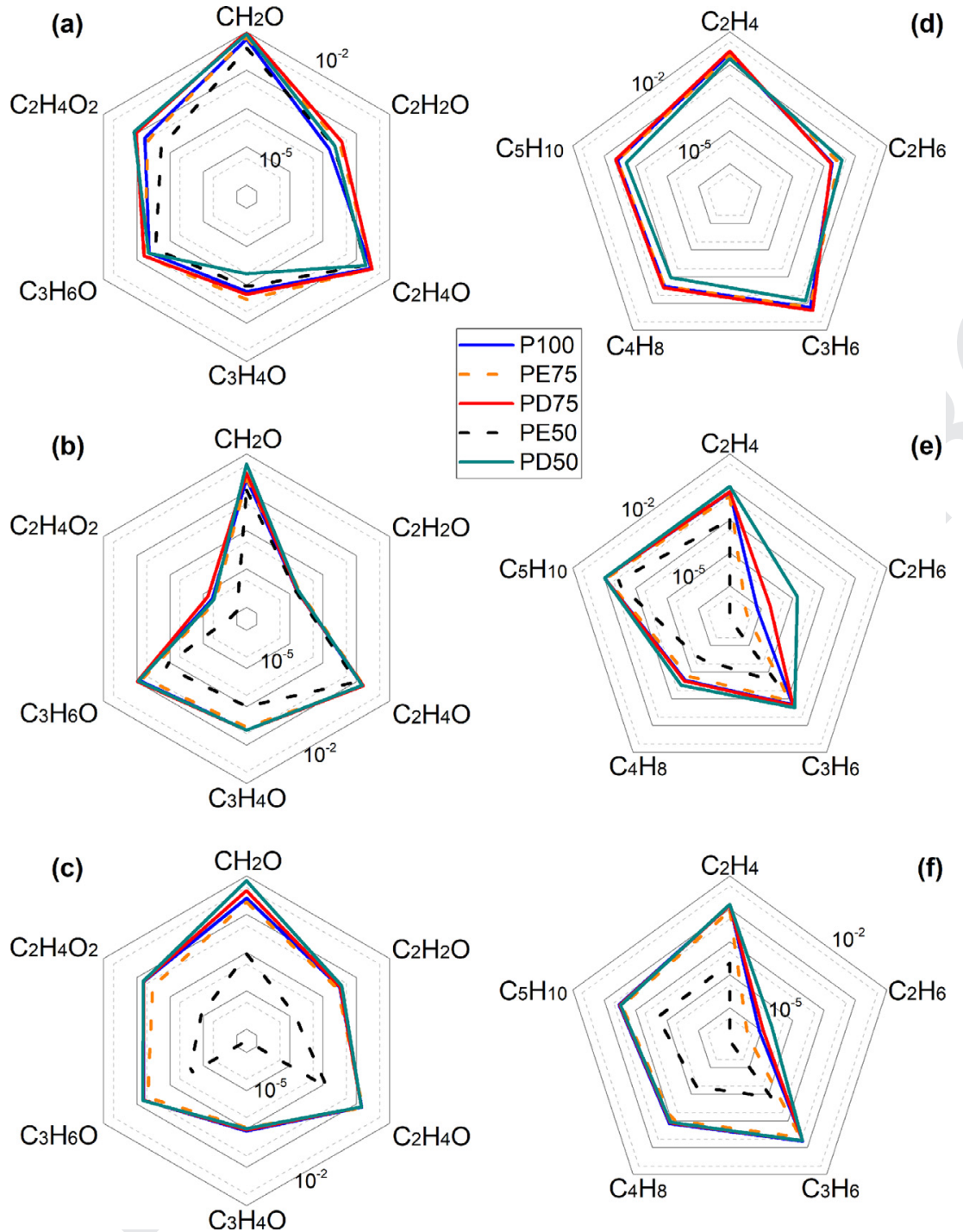

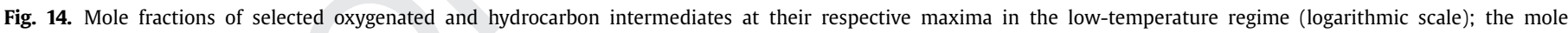

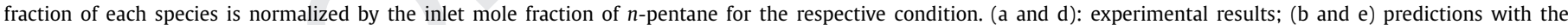
NUIG model; (c and f) predictions with the Polimi model.

eral efficiency of formaldehyde formation but favors the unimolecular decomposition of $\mathbf{P 8 - 2}$. The production of formaldehyde in the ethanol-containing blends is therefore altered to the reaction sequence 2-hydroperoxy-4-pentanone $\left(\mathrm{C}_{5} \mathrm{H}_{10} \mathrm{O}_{3}\right.$, P82) $\rightarrow$ 2-pentanoxide-4-one $\left(\mathrm{C}_{5} \mathrm{H}_{9} \mathrm{O}_{2}, \mathbf{P 1 0}-2\right) \rightarrow \mathrm{CH}_{3} \mathrm{COCH}_{2} \quad\left(\mathrm{C}_{3} \mathrm{H}_{5} \mathrm{O}\right.$, acetonyl $) \rightarrow \mathrm{CH}_{3} \mathrm{COCH}_{2} \mathrm{O} \quad\left(\mathrm{C}_{3} \mathrm{H}_{5} \mathrm{O}_{2}\right) \rightarrow \mathrm{CH}_{2} \mathrm{O} \quad(\mathbf{F A L})$, compare also Fig. 3.

\subsubsection{Further intermediates}

While the previous analysis has focused on the fuel decomposition schemes and small oxygenated species, a number of further intermediates has also been detected, and selected species are presented in Fig. 14, with experimental results in panels (a and d) and predictions with the NUIG and Polimi models in panels (b,e and c,f). Again, all mole fractions (in the $n$-pentane-containing mixtures) have been normalized by the inlet mole fraction of $n$ pentane for the respective conditions. The maximum values of all species in the NTC zone are grouped in order to illustrate the selectivity of $n$-pentane reaction pathways impacted by the addition of DME or ethanol. Please note that full temperature-dependent mole fraction profiles over the entire range from 450 to $900 \mathrm{~K}$ are provided, together with simulations with the NUIG model, in Figs.
S14-S21 in SM2. In general, the shapes of these profiles are reasonably well predicted. However, with an emphasis on the experiment and on the low-temperature reactions in the dual-fuel mixtures, we will limit the discussion here to some aspects in the LTC region. Due to the normalization, mole fraction values should agree if there were no interactive effects. Inspection of the patterns in Fig. 14 reveals some important differences between experimental and modeling results.

Figure 14a-c compares experiment and model predictions for selected oxygenated intermediates. Since acetic acid is the major acid produced in the oxidation of $n$-pentane [39], it is identified as the dominant isomer of $\mathrm{C}_{2} \mathrm{H}_{4} \mathrm{O}_{2}$ in P100, PE75, and PE50. However, methyl formate is the oxidation product of DME with the formula of $\mathrm{C}_{2} \mathrm{H}_{4} \mathrm{O}_{2}$ [51,54], which is also observed in this experiment. Therefore, with the addition of DME, methyl formate becomes the major isomer of $\mathrm{C}_{2} \mathrm{H}_{4} \mathrm{O}_{2}$. However, due to lacking EI cross sections of methyl formate, $\mathrm{C}_{2} \mathrm{H}_{4} \mathrm{O}_{2}$ has been calibrated as acetic acid in all experiments. Hydroxyacetaldehyde would be another isomer, but there is no known pathway how it could be formed and it seems kinetically unlikely. Compared to the modeling results, this species is well-predicted by the Polimi model but highly under-predicted by NUIG model. Bugler et al. [39] also 
(a)

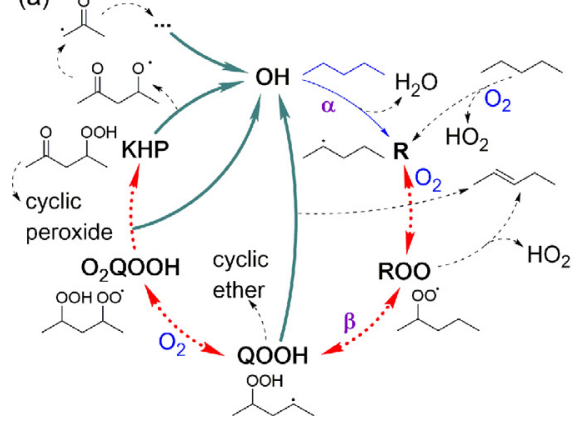

(b)

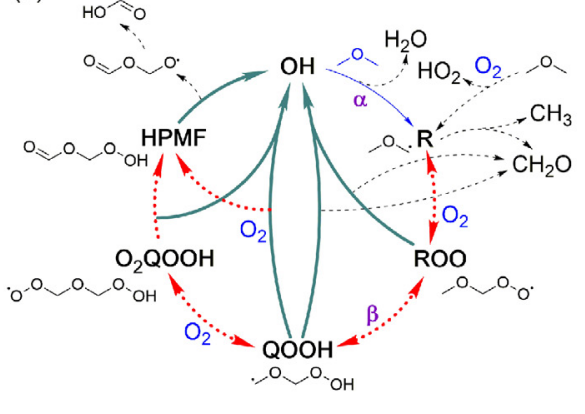

(c)

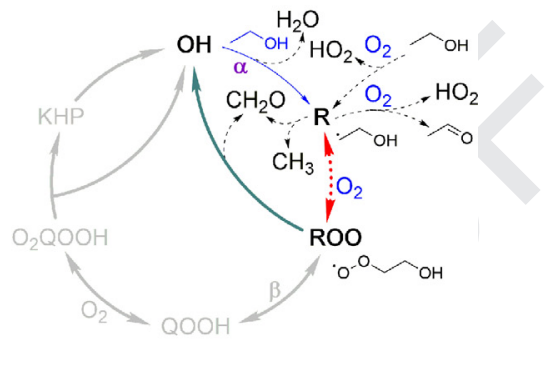

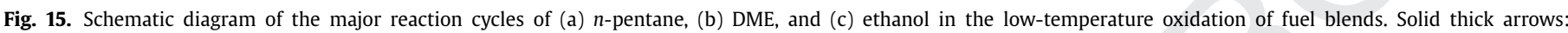

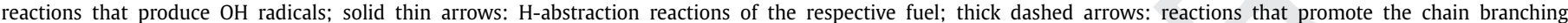

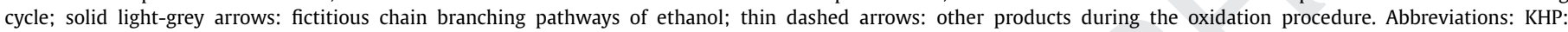
ketohydroperoxide of $n$-pentane, HPMF: hydroperoxymethyl formate.

reported the under-prediction of their measurement of $\mathrm{C}_{2} \mathrm{H}_{4} \mathrm{O}_{2}$ in the oxidation of $n$-pentane in a JSR.

The further species in Fig. 14a-c are single oxygenated species of the sum formula $\mathrm{C}_{n} \mathrm{H}_{2 n} \mathrm{O}$ that can be assigned to cyclic ethers, aldehydes, and ketones, and $\mathrm{C}_{\mathrm{n}} \mathrm{H}_{2 \mathrm{n}-2} \mathrm{O}$ that are probably ketenes. $\mathrm{CH}_{2} \mathrm{O}$ can only be formaldehyde, $\mathrm{C}_{2} \mathrm{H}_{2} \mathrm{O}$ obviously is ketene, and $\mathrm{C}_{3} \mathrm{H}_{4} \mathrm{O}$ has been calibrated as methyl ketene. According to previous analysis with GC, CRDS, and FTIR [39], $\mathrm{C}_{2} \mathrm{H}_{4} \mathrm{O}$ was separated for oxirane and acetaldehyde, but is here calibrated only as acetaldehyde due to missing distinction of isomers. In Ref. [39], $\mathrm{C}_{3} \mathrm{H}_{6} \mathrm{O}$ was identified as propanal, acetone, 2-methyloxirane, and oxetane, here it is calibrated as acetone. In general, aldehyde compounds could be produced from the decomposition of the $\mathrm{C}_{5}$-hydroperoxides or ketohydroperoxides by breaking the $\mathrm{O}-\mathrm{OH}$ bond in the hydroperoxy group. Cyclic ethers are usually formed via the reactions of $\mathrm{QOOH}$ radicals. Looking at the tendencies in Fig. 14a-c in both experimental and modeling results, identical selectivity is observed in both experiment and Polimi model predictions among different $\mathrm{C}_{\mathrm{n}} \mathrm{H}_{2 n} \mathrm{O}$ and $\mathrm{C}_{\mathrm{n}} \mathrm{H}_{2 n-2} \mathrm{O}$ species under different inlet condition except for PE50. The NUIG model predictions for $\mathrm{CH}_{2} \mathrm{O}, \mathrm{C}_{2} \mathrm{H}_{4} \mathrm{O}$ and $\mathrm{C}_{3} \mathrm{H}_{6} \mathrm{O}$ are closer to the experimental values than those for the other shown species, with substantial deviations especially for $\mathrm{C}_{2} \mathrm{H}_{2} \mathrm{O}$ (ketene) and $\mathrm{C}_{2} \mathrm{H}_{4} \mathrm{O}_{2}$ (acetic acid), see also Figs. S14 and $\mathrm{S} 17$ in SM2.

Figure $14 \mathrm{~d}-\mathrm{f}$ presents the experimental and modeling results for selected alkanes and alkenes. Pentene $\left(\mathrm{C}_{5} \mathrm{H}_{10}\right.$, calibrated as 1-pentene), propene $\left(\mathrm{C}_{3} \mathrm{H}_{6}\right)$, and ethene $\left(\mathrm{C}_{2} \mathrm{H}_{4}\right)$ are major intermediates. Both models well predict the formation of pentene and ethene, but under-predict the formation of butene $\left(\mathrm{C}_{4} \mathrm{H}_{8}\right.$, here calibrated as 1-butene) and propene. A uniform selectivity can be found among these species in different conditions in Fig. $14 \mathrm{~d}-\mathrm{f}$, except for ethane $\left(\mathrm{C}_{2} \mathrm{H}_{6}\right)$, for which experiment and model reveal opposite tendencies with the addition of DME and ethanol. As observed in the formation of hydroperoxymethane (Fig. 9), the methyl radical formed in the decomposition of DME undergoes the recombination to ethane, but not the reaction with $\mathrm{O}_{2}$. Since ethane is under-predicted by a factor of 100 in P100, a significant difference can be observed by the addition of DME for the modeling result, but not in the experiment.

\subsection{Selected aspects influencing the reactivity}

To inspect the reactivity of the dual-fuel mixtures further, the known major low-temperature oxidation cycles for the three individual fuels are shown schematically in Fig. 15. For all cycles, the solid thick arrows show reactions that produce $\mathrm{OH}$ radicals, while the solid thin arrows indicate $\mathrm{OH}$-consumption. To obtain the maximum of $\mathrm{OH}$ being produced from one complete cycle, the solid thick arrows after the second $\mathrm{O}_{2}$ addition (behind $\mathrm{O}_{2} \mathrm{QOOH}$ ) need to be considered as all other reactions producing $\mathrm{OH}$ before this step lead to a termination of the cycle.

As seen in Fig. 15a for $n$-pentane, the two-step $\mathrm{O}_{2}$ addition reaction sequence from the fuel could yield three $\mathrm{OH}$ radicals (solid thick arrows after $\mathrm{O}_{2} \mathrm{QOOH}$ ), while it consumes only one $\mathrm{OH}$ radical in its pentyl radical production process via $\mathrm{H}$-abstraction reactions (solid thin arrow). The $\alpha$-step is the most important $n$ pentane consumption reaction, which may be in strong competition in the fuel blends or with other primary intermediates during the reaction process.

$\mathrm{OH}$ is the dominant initial radical for the recurrence of the branching process of DME. As shown in Fig. 15b, a maximum of two $\mathrm{OH}$ radicals could be produced through one cycle (solid thick arrows after $\mathrm{O}_{2} \mathrm{QOOH}$ ), while also only one $\mathrm{OH}$ is consumed by the DME radical formation (solid thin arrow). However, in the $\alpha$ step, a strong competition from $n$-pentane impacts the consumption of $\mathrm{OH}$ radicals. When the more reactive fuel DME is added to $n$-pentane, $\mathrm{OH}$ radicals could be produced at lower temperatures, thus promoting the system's reactivity. However, the maximum conversion of $n$-pentane keeps almost the same with the addition of DME (compare Fig. 2a), which means that the consumption of $\mathrm{OH}$ radicals by $n$-pentane does not significantly increase. This may be due to the similar concentration of $\mathrm{OH}$ radicals at identical equivalence ratio, or $n$-pentane taking advantage over DME in the competition of $\mathrm{OH}$ radical reactions.

Figure $15 c$ shows the reactions of ethanol in the lowtemperature region. The light-grey arrows indicate a fictitious second $\mathrm{O}_{2}$ addition that cannot happen because of ethanol's molecular structure. Therefore, ethanol consumes one $\mathrm{OH}$ radical (solid thin arrow), and produces almost none in its reaction recurrence, as the ROO is very unlikely to be formed. Since ethanol plays the role of an $\mathrm{OH}$ radical consumer in $n$-pentane/ethanol mixtures, it sufficiently reduces the pool of active radicals and inhibits the general reactivity of the whole system.

As discussed above, the $\mathrm{OH}$ radical plays an important role in the $\mathrm{H}$-abstraction of $n$-pentane, DME, and ethanol during the ignition progress in the low-temperature regime. $\mathrm{H}$-abstraction reactions, especially with $\mathrm{OH}$, are the first step turning $\mathrm{RH}\left(\mathrm{C}_{5} \mathrm{H}_{12}\right.$ $\mathrm{DME}$, or EtOH) into the $\mathrm{R}$ radical. It is interesting to view the balance of $\mathrm{OH}$ and $\mathrm{HO}_{2}$, another prominent radical associated with low-temperature reactions. Fig. 16 shows the simulated mole fraction ratio of $\mathrm{OH} / \mathrm{HO}_{2}$ for all fuel conditions. It is the ratio between the maxima of $\mathrm{OH}$ and $\mathrm{HO}_{2}$ radicals along the flow reactor at each temperature point in the range of $475-750 \mathrm{~K}$.

According to both, NUIG and Polimi models, the mole fraction of the $\mathrm{OH}$ radical is $\sim 10^{-8}$ in the NTC zone, and that of the $\mathrm{HO}_{2}$ radical is $\sim 10^{-5}$ in that zone, corresponding to the high reactiv- 


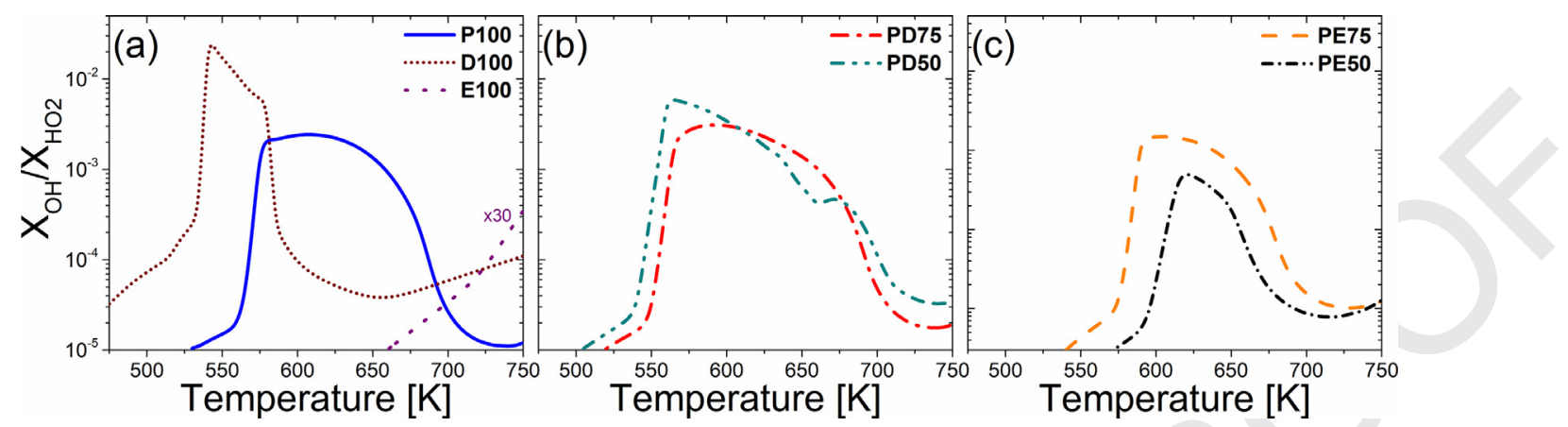

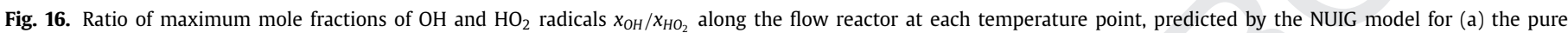
fuels, (b) the mixtures of $n$-pentane and DME, and (c) the mixtures of $n$-pentane and ethanol.

ity of $\mathrm{OH}$ in the $\mathrm{H}$-abstraction reactions. For the neat fuels, the $x_{\mathrm{OH}} / x_{\mathrm{HO} 2}$ ratio is highest for DME at very low temperatures of 480$580 \mathrm{~K}$. After a slow but steady rise in this region, a steep increase occurs around $540 \mathrm{~K}$, coincident with the DME low-temperature consumption maximum (see Fig. 2e). With rising temperature, the low-temperature kinetics slows down and chain-terminating reactions become of increasing importance. After a steep increase in $\mathrm{OH}$ production at about $560 \mathrm{~K}$ for $n$-pentane, approximately in the zone where low-temperature fuel consumption accelerates (see Fig. 2a), a plateau is reached that represents the competing reactions in the NTC region. Similar approximately constant values of the $x_{\mathrm{OH}} / x_{\mathrm{HO} 2}$ ratio are also evident in the intermediate temperature range of about $570-670 \mathrm{~K}$ for DME and the $n$-pentane/DME mixtures in Fig. 16b. As discussed before, ethanol shows a much lower relative $\mathrm{OH}$ production in the low-temperature regime, with a rise of the $x_{\mathrm{OH}} / x_{\mathrm{HO} 2}$ ratio only noted above $650 \mathrm{~K}$ with much lower values than for the other two fuels, and it should be remembered that no significant low-temperature fuel consumption was noted in this case (see Fig. 2f). Ethanol-containing mixtures with $n$-pentane exhibit a significantly increased $\mathrm{OH}$ production around $580 \mathrm{~K}$ for PE75 and $600 \mathrm{~K}$ for PE50, approximately near the respective start of fuel consumption; a plateau at higher temperatures up to $650 \mathrm{~K}$ can also be noted for these mixtures (Fig. 16c). The formation and consumption of $\mathrm{OH}$ radicals based on the reaction cycles in Fig. 15 can contribute to the understanding of the lowtemperature system reactivity; more details on the efficiency of $\mathrm{OH}$ production following a similar analysis of Dames et al. [8] and Merchant et al. [18] for propane and propane/DME mixtures are also provided in Section S6 of SM2. They support the strong decrease in low-temperature reactivity for ethanol addition to n-pentane and show a small tendency of higher $\mathrm{OH}$ yield in the $n$-pentane/DME mixtures. It must be noted, however, that an assessment of the total $\mathrm{OH}$ production in the system may explain some features of the dual-fuel behavior, especially when systems with quite different low-temperature reactivity are considered. For the $n$-pentane/DME mixtures that show synergistic effects, these cannot be understood in terms of the $\mathrm{OH}$ balance alone but need to consider the formed fuel radicals and other early intermediates and their secondary reactions. For this reason, sensitivity analyses of $\mathrm{OH}$ were performed with the NUIG model for P100, PD75, and PD50 at 25\% n-pentane conversion and are provided in Fig. 17.

The results also show the interaction of $n$-pentane and DME via the competition of the $\mathrm{OH}$ radical. In general, $\mathrm{H}$-abstraction of $n$-pentane at the $\gamma$-site shows the highest negative coefficient, since for this radical it is most difficult to form new $\mathrm{OH}$ radicals in its further reactions. Upon DME addition, the abstraction reactions at the other two sites of $n$-pentane by $\mathrm{OH}$ radicals reduce their positive sensitivity or even turn to negative values. Second $\mathrm{O}_{2}$-addition reactions have stronger sensitivities than the first $\mathrm{O}_{2}$ addition step. The unimolecular decomposition reaction of the $\mathrm{C}_{5}$ -

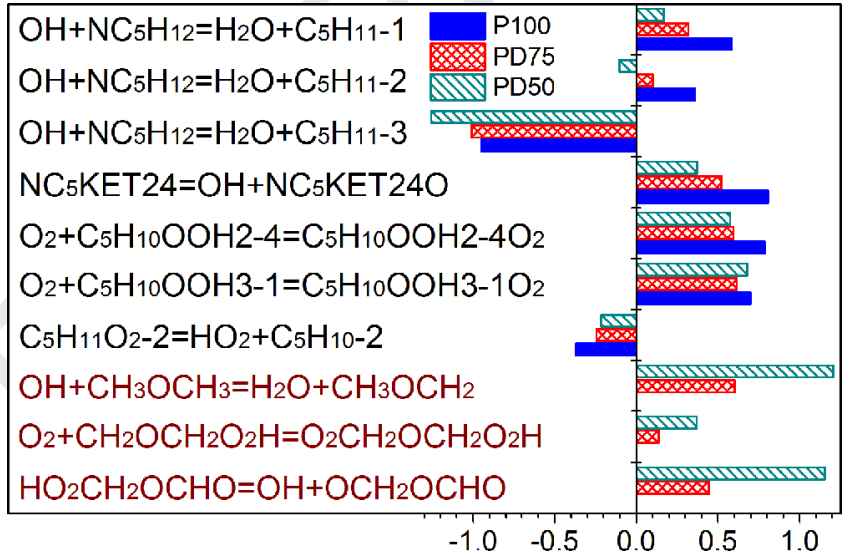

Fig. 17. Sensitivity coefficient for $\mathrm{OH}$ to reaction rate pre-exponential factors at $25 \% n$-pentane conversion (NUIG model). Abbreviations: $\mathrm{NC}_{5} \mathrm{KET} 24$ is 2hydroperoxy-4-pentanone (P8-2), $\mathrm{NC}_{5}$ KET240 is the 2-pentanoxide-4-one radical (P10-2), $\mathrm{C}_{5} \mathrm{H}_{10} \mathrm{OOH} 2-4$ is the 2-hydroperoxy-4-pentyl radical, $\mathrm{C}_{5} \mathrm{H}_{10} \mathrm{OOH} 2-4 \mathrm{O}_{2}$ is the 2-hydroperoxy-4-pentylperoxy radical, $\mathrm{C}_{5} \mathrm{H}_{10} \mathrm{OOH} 3-1$ is the 3-hydroperoxy-1-pentyl radical, $\mathrm{C}_{5} \mathrm{H}_{10} \mathrm{OOH} 3-1 \mathrm{O}_{2}$ is the 3-hydroperoxy-1-pentylperoxy radical, $\mathrm{C}_{5} \mathrm{H}_{11} \mathrm{O}_{2}-2$ is the 2-pentylperoxy radical (P3-2), and $\mathrm{C}_{5} \mathrm{H}_{10}-2$ is 2-pentene (P5-2); compare also nomenclature and structures in Table S1 in SM2.

ketohydroperoxide (P8), forming one $\mathrm{OH}$ radical, becomes slightly less important with the doping of DME, whilst the H-abstraction reaction of DME and the decomposition of HPMF (D8) become very sensitive reactions for the mixture conditions, of increasing importance with higher DME fraction. Especially the formation and decomposition reactions of the ketohydroperoxide of the respective fuel are thus important pathways in the formation of $\mathrm{OH}$ radicals influencing the overall reactivity of the system.

\section{Summary and perspectives}

The low-temperature oxidation of mixtures of $n$-pentane with the oxygenated $\mathrm{C}_{2} \mathrm{H}_{6} \mathrm{O}$ fuel isomers dimethyl ether and ethanol, including that of the three individual fuels, was experimentally investigated in a flow reactor at an equivalence ratio of 0.7 and atmospheric pressure, covering the temperature range of $450-930 \mathrm{~K}$. Electron ionization molecular-beam mass spectrometry was used to provide a detailed species overview under all conditions, with quantitative evaluation as mole fraction profiles whenever possible. In cases where only relative signal intensities could be provided, trends between the individual fuels and the mixtures could be identified. The overall reactivity of the fuels and their mixtures was discussed, considering the very different low-temperature behavior of the three individual fuels. To emphasize interactive effects of the $\mathrm{C}_{2} \mathrm{H}_{6} \mathrm{O}$ isomers in the blends with $n$-pentane, normalization on the $n$-pentane inlet mole fractions was performed. 
Ethanol, as a fuel that exhibits only marginal low-temperature reactivity, is a significant consumer of active free radicals and thus inhibits the oxidation process in the mixtures, whilst the mixture of two reactive fuels, $n$-pentane and DME, presents noticeable synergistic effects where the maximum conversion of both $n$-pentane and DME is improved in the mixtures compared to the pure fuels.

For a deeper albeit preliminary understanding of the effects in the LTC of the dual-fuel mixtures, two current models, namely the NUIG and the Polimi models that can both be considered well examined for the individual fuels were adopted in simulations for all conditions. Both models were seen to perform reasonably well regarding the fuel consumption and major species formation for the individual fuels, but the predictions of temperature shifts and synergistic effects, especially in the oxidation behavior of the mixtures leave room for improvement. Such further developments can in part be considered for the simulation of two-dimensional effects and heat transfer in the flow reactor with more refined models than used in these preliminary predictions, especially in zones with very temperature-sensitive reactions.

The oxidation chemistry in the fuel mixtures was analyzed in more detail on the basis of the reaction pathways of the individual fuel components by following the sequence of initial fuel decomposition products and their further reactions by means of intermediate species profiles. Mole fractions of oxygenated intermediates as well as selected hydrocarbon species were presented with an emphasis on the zone of the initial fuel conversion and NTC region in the mixtures, and trends between experiment and model were compared, resulting in an overall somewhat diverse picture. While many trends seen in the experiments upon blending of $n$ pentane with either one of the two isomers are quite well reproduced by these preliminary simulations, the magnitude of the effects is not always correctly predicted, and large discrepancies are seen for some intermediates.

Regarding the reactivity of the system, the $\mathrm{OH}$ balance as well as the ratio of $\mathrm{OH}$ and $\mathrm{HO}_{2}$, both important intermediates in the low-temperature oxidation zone, were inspected to assist understanding of some aspects of the interactions for the dual-fuel mixtures. The $\mathrm{OH}$ competition between $n$-pentane and ethanol, two fuels with very different low-temperature reactivity, seems simpler than between $n$-pentane and DME that both show lowtemperature reactions with different production cycles of $\mathrm{OH}$. Secondary products such as alkyl radicals could participate in this $\mathrm{OH}$ competition by enhancement of $\mathrm{O}_{2}$ addition reactions that in turn can contribute to $\mathrm{OH}$ radical production. Because they are involved in the formation of $\mathrm{OH}$ radicals, acetaldehyde, hydroperoxyethane, and especially hydroperoxymethane, could also be considered as indicative species of the reactivity of the fuel mixture. Interactive effects between the reactive species provided in the fuel mixtures may result in a higher maximum conversion of both fuels than found for each of them individually.

The work presented here suggests several areas for further work. As seen in some cases, the nature of the isomer composition might change for the fuel blends, with $\mathrm{C}_{2} \mathrm{H}_{4} \mathrm{O}_{2}$ as one example that should be predominantly acetic acid for $n$-pentane and methyl formate for DME oxidation. Isomer-resolved, quantitative species analysis over the critical temperature range between about 500 and $650 \mathrm{~K}$ for these dual-fuel mixtures is thus recommended as a further continuation of this work. It would be especially useful if it provided detailed data on first fuel decomposition products and highly oxygenated species. Furthermore, in spite of recent model development and ample knowledge on the oxidation of the three individual fuels in the literature, it seems that interactive effects cannot be fully captured and might need more accurate determination of critical reaction parameters in the low-temperature zone where the initial fuel consumption accelerates. Temperature dependences may need to be inspected with care. As one indicator for such needs, it is interesting to note that the rate expressions 1005 for the $\mathrm{H}$-abstraction reactions by $\mathrm{OH}$ for the three individual fuels 1006 exhibit important differences in both tested models. Since reliable 1007 predictions for the oxidation behavior of mixtures of alkane fuels 1008 with ethanol or DME - or more generally of hydrocarbon with oxy- 1009 genated fuels - are highly desirable, we hope that the presented 1010 experimental dataset will contribute to the further improvement 1011 of models for such dual-fuel mixtures.

1012

\section{Acknowledgments}

The authors wish to thank the Deutsche Forschungsgemein- 1014 schaft (DFG) for support of this work under contract KO1363/31- 1015 1. $\mathrm{HJ}$ is grateful for a fellowship of the Alexander von Humboldt 1016 $(\mathrm{AvH})$ Foundation that supported his research period in Bielefeld. 1017 Helpful discussions with Dr. Luc-Sy Tran, now at Lille University, 1018 during his research period as an AvH Fellow in Bielefeld are grate- 1019 fully acknowledged. Furthermore, the authors wish to thank Prof. 1020 Yiguang Ju, Princeton University, USA, for his profound and contin- 1021 uous interest in this work, for insightful discussions and for host- 1022 ing $\mathrm{HJ}$ for a research stay in his group.

\section{Supplementary materials}

Supplementary material associated with this article can be 1025 found, in the online version, at doi:10.1016/j.combustflame.2018.03. 1026 003.

\section{References}

[1] A.K. Agarwal, Biofuels (alcohols and biodiesel) applications as fuels for internal 1029 combustion engines, Prog. Energy Combust. Sci. 33 (2007) 233-271.

[2] W. Leitner, J. Klankermayer, S. Pischinger, H. Pitsch, K. Kohse-Höinghaus, Ad- 1031 vanced biofuels and beyond: chemistry solutions for propulsion and produc- 1032 tion, Angew, Chem. Int. Ed. 129 (2017) 5500-5544. 1033

[3] X. Lu, D. Han, Z. Huang, Fuel design and management for the control of ad- 1034 vanced compression-ignition combustion modes, Prog. Energy Combust. Sci. 371035 (2011) 741-783. 1036

[4] S. Kokjohn, R. Hanson, D. Splitter, J. Kaddatz, R. Reitz, Fuel reactivity controlled 1037 compression ignition (RCCI) combustion in light- and heavy-duty engines, SAE 1038 Int. J. Fuels Lubr. 4 (2011) pp. 2011-01-0357.

[5] S. Saxena, I.D. Bedoya, Fundamental phenomena affecting low temperature 1040 combustion and HCCI engines, high load limits and strategies for extending 1041 these limits, Prog. Energy Combust. Sci. 39 (2013) 457-488. 1042

[6] B. Prabhakar, S. Jayaraman, R. Vander Wal, A. Boehman, Experimental studies 1043 of high efficiency combustion with fumigation of dimethyl ether and propane 1044 into diesel engine intake air, J. Eng. Gas Turb. Power 137 (2015) 41505.

[7] U. Burke, K.P. Somers, P. O'Toole, C.M. Zinner, N. Marquet, G. Bourque, E.L. Pe- 1046 tersen, W.K. Metcalfe, Z. Serinyel, H.J. Curran, An ignition delay and kinetic 1047 modeling study of methane, dimethyl ether, and their mixtures at high pres- 1048 sures, Combust. Flame 162 (2015) 315-330. 1049

[8] E.E. Dames, A.S. Rosen, B.W. Weber, C.W. Gao, C.-J. Sung, W.H. Green, 1050 A detailed combined experimental and theoretical study on dimethyl 1051 ether/propane blended oxidation, Combust. Flame 168 (2016) 310-330. 1052

[9] M. Cord, B. Husson, J.C. Lizardo Huerta, O. Herbinet, P.-A. Glaude, R. Fournet, 1053 B. Sirjean, F. Battin-Leclerc, M. Ruiz-Lopez, Z. Wang, M. Xie, Z. Cheng, F. Qi, 1054 Study of the low temperature oxidation of propane, J. Phys. Chem. A 116 (2012) 1055 12214-12228.

[10] M. Cord, B. Sirjean, R. Fournet, A. Tomlin, M. Ruiz-Lopez, F. Battin-Leclerc, Im- 1057 provement of the modelling of the low-temperature oxidaton of $n$-butane - 1058 Study of the primary reactions, J. Phys. Chem. A 116 (2012) 6142-6158. 1059

[11] C. Bahrini, P. Morajkar, C. Schoemaecker, O. Frottier, O. Herbinet, P.-A. Glaude, 1060 F. Battin-Leclerc, C. Fittschen, Experimental and modeling study of the oxida- 1061 tion of $n$-butane in a jet stirred reactor using cw-CRDS measurements, Phys. 1062 Chem. Chem. Phys. 15 (2013) 19686-19698.

[12] F. Battin-Leclerc, O. Herbinet, P.-A. Glaude, R. Fournet, Z. Zhou, L. Deng, H. Guo, 1064 M. Xie, F. Oi, Experimental confirmation of the low-temperature oxidation 1065 scheme of alkanes, Angew. Chem. Int. Ed. 49 (2010) 3169-3172. 1066

[13] O. Herbinet, F. Battin-Leclerc, S. Bax, H. Le Gall, P.-A. Glaude, R. Fournet, 1067 Z. Zhou, L. Deng, H. Guo, M. Xie, F. Qi, Detailed product analysis during the 1068 low temperature oxidation of n-butane, Phys. Chem. Chem. Phys. 13 (2011) 1069 296-308.

[14] D. Healy, N.S. Donato, C.J. Aul, E.L. Petersen, C.M. Zinner, G. Bourque, H.J. Cur- 1071 ran, $n$-Butane: ignition delay measurements at high pressure and detailed 1072 chemical kinetic simulations, Combust. Flame 157 (2010) 1526-1539. 1073

[15] D. Healy, D.M. Kalitan, C.J. Aul, E.L. Petersen, G. Bourque, H.J. Curran, Oxidation 1074 of C1-C5 alkane quinternary natural gas mixtures at high pressures, Energy 1075 Fuels 24 (2010) 1521-1528. 
[16] D. Healy, M.M. Kopp, N.L. Polley, E.L. Petersen, G. Bourque, H.J. Curran, Methane/n-butane ignition delay measurements at high pressure and detailed chemical kinetic simulations, Energy Fuels 24 (2010) 1617-1627.

[17] E. Ranzi, A. Cuoci, A. Frassoldati, M. Pelucchi, T. Faravelli, New reaction classes in the kinetic modeling of low temperature oxidation of n-alkanes, Combust. Flame 162 (2015) 1679-1691.

[18] S.S. Merchant, C.F. Goldsmith, A.G. Vandeputte, M.P. Burke, S.J. Klippenstein, W.H. Green, Understanding low-temperature first-stage ignition delay: Propane, Combust. Flame 162 (2015) 3658-3673.

19] P. Saisirirat, C. Togbé, S. Chanchaona, F. Foucher, C. Mounaim-Rousselle, P. Dagaut, Auto-ignition and combustion characteristics in HCCI and JSR using 1 -butanol $/ n$-heptane and ethanol $/ n$-heptane blends, Proc. Combust. Inst. 33 (2011) 3007-3014

[20] P. Saisirirat, F. Foucher, S. Chanchaona, C. Mounaïm-Rousselle, Spectroscopic measurements of low-temperature heat release for homogeneous combustion compression ignition (HCCI) n-heptane/alcohol mixture combustion, Energy Fuels 24 (2010) 5404-5409.

[21] M. Pelucchi, M. Bissoli, C. Cavallotti, A. Cuoci, T. Faravelli, A. Frassoldati, E. Ranzi, A. Stagni, Improved kinetic model of the low-temperature oxidation of $n$-heptane, Energy Fuels 28 (2014) 7178-7193.

[22] D.M.A. Karwat, S.W. Wagnon, M.S. Wooldridge, C.K. Westbrook, Lowtemperature speciation and chemical kinetic studies of $n$-heptane, Combust. Flame 160 (2013) 2693-2706.

[23] O. Herbinet, B. Husson, Z. Serinyel, M. Cord, V. Warth, R. Fournet, P.-A. Glaude, B. Sirjean, F. Battin-Leclerc, Z. Wang, M. Xie, Z. Cheng, F. Qi, Experimental and modeling investigation of the low-temperature oxidation of $n$-heptane, Combust. Flame 159 (2012) 3455-3471.

[24] R. Di Sante, Measurements of the auto-ignition of $n$-heptane/toluene mixtures using a rapid compression machine, Combust. Flame 159 (2012) 55-63.

[25] G.E. Bogin Jr., A. DeFilippo, J.Y. Chen, G. Chin, J. Luecke, M.A. Ratcliff, B.T. Zigler, A.M. Dean, Numerical and experimental investigation of $n$-heptane autoignition in the ignition quality tester (IQT), Energy Fuels 25 (2011) 5562-5572.

[26] M. Ribaucour, R. Minetti, L.R. Sochet, H.J. Curran, W.J. Pitz, C.K. Westbrook, Ignition of isomers of pentane: an experimental and kinetic modeling study, Proc. Combust. Inst. 28 (2000) 1671-1678.

[27] R. Minetti, A. Roubaud, E. Therssen, M. Ribaucour, L.R. Sochet, The chemistry of pre-ignition of n-pentane and 1-pentene, Combust. Flame 118 (1999) 213-220.

[28] C.K. Westbrook, H.J. Curran, W.J. Pitz, J.F. Griffiths, C. Mohamed, S.K. Wo, The effects of pressure, temperature, and concentration on the reactivity of alkanes: experiments and modeling in a rapid compression machine, Symp. (Int.) Combust. 27 (1998) 371-378.

[29] M. Ribaucour, R. Minetti, L.R. Sochet, Autoignition of n-pentane and 1-pentene: experimental data and kinetic modeling, Symp. (Int.) Combust. 27 (1998) 345351.

[30] J.F. Griffiths, P.A. Halford-Maw, C. Mohamed, Spontaneous ignition delays as a diagnostic of the propensity of alkanes to cause engine knock, Combust. Flame 111 (1997) 327-337.

[31] R. Minetti, M. Ribaucour, M. Carlier, L.R. Sochet, Autoignition delays of a series of linear and branched chain alkanes in the intermediate range of temperature, Combust. Sci. Technol. 113-114 (1996) 179-192.

[32] A. Cox, J.F. Griffiths, C. Mohamed, H.J. Curran, W.J. Pitz, C.K. Westbrook, Extents of alkane combustion during rapid compression leading to single- and twostage ignition, Symp. (Int.) Combust. 26 (1996) 2685-2692.

[33] J.F. Griffiths, P.A. Halford-Maw, D.J. Rose, Fundamental features of hydrocarbon autoignition in a rapid compression machine, Combust. Flame 95 (1993) 291306.

[34] B. Marks, O. Mathieu, R. Archuleta, E.L. Petersen, J. Bugler, A. Heufer, H. Curran, Ignition delay time measurements and modeling of $n$-pentane and iso-pentane at elevated pressures, 51st AIAA Aerospace Science Meeting (2013).

[35] J. Bugler, B. Marks, O. Mathieu, R. Archuleta, A. Camou, C. Grégoire, K.A. Heufer, E.L. Petersen, H.J. Curran, An ignition delay time and chemical kinetic modeling study of the pentane isomers, Combust. Flame 163 (2016) 138-156.

[36] V.P. Zhukov, V.A. Sechenov, A.Y. Starikovskii, Self-ignition of a lean mixture of $n$-pentane and air over a wide range of pressures, Combust. Flame 140 (2005) 196-203.

[37] A. Chakir, M. Bellimam, J.C. Boettner, M. Cathonnet, Kinetic study of n-pentane oxidation, Combust. Sci. Technol. 77 (1991) 239-260.

[38] V. Simon, Y. Simon, G. Scacchi, F. Baronnet, Étude expérimentale et modélisation des réactions d'oxydation du $n$-pentane et du cyclopentane, Can. J. Chem. 75 (1997) 575-584.

[39] J. Bugler, A. Rodriguez, O. Herbinet, F. Battin-Leclerc, C. Togbé, G. Dayma, P. Dagaut, H.J. Curran, An experimental and modelling study of n-pentane oxidation in two jet-stirred reactors: The importance of pressure-dependent kinetics and new reaction pathways, Proc. Combust. Inst. 36 (2017) 441-448.

40] A. Rodriguez, O. Herbinet, Z. Wang, F. Qi, C. Fittschen, P.R. Westmoreland, F. Battin-Leclerc, Measuring hydroperoxide chain-branching agents during npentane low-temperature oxidation, Proc. Combust. Inst. 36 (2017) 333-342.

[41] Z. Wang, X. Zhang, L. Xing, L. Zhang, F. Herrmann, K. Moshammer, F. Qi, K. Kohse-Höinghaus, Experimental and kinetic modeling study of the low- and intermediate-temperature oxidation of dimethyl ether, Combust. Flame 162 (2015) 1113-1125.

42] K. Kohse-Höinghaus, P. Oßwald, T.A. Cool, T. Kasper, N. Hansen, F. Qi, C.K. Westbrook, P.R. Westmoreland, Biofuel combustion chemistry: from ethanol to biodiesel, Angew. Chem. Int. Ed. 49 (2010) 3572-3597.
[43] W. Ying, Z. Longbao, Performance and emissions of a compression-ignition 1161 engine fueled with dimethyl ether and rapeseed oil blends, Energy Fuels 211162 (2007) 1454-1458.

[44] Y. Tsutsumi, K. Hoshina, A. rijima, H. Shoji, Analysis of the combustion characteristics of a HCCI engine operating on DME and methane, SAE Tech. Pap. 1165 2007-65-41 (2007)

[45] M. Konno, Z. Chen, Ignition mechanisms of HCCI combustion process fueled 1167 with methane/DME composite fuel, SAE Tech. Pap. 2005-01-01 (2005). 1168

[46] U. Pfahl, K. Fieweger, G. Adomeit, Self-ignition of diesel-relevant hydrocarbon- 1169 air mixtures under engine conditions, Symp. (Int.) Combust. 26 (1996) 781- 1170 789.

[47] N. Kurimoto, B. Brumfield, X. Yang, T. Wada, P. Diévart, G. Wysocki, Y. Ju, Quan- 1172 titative measurements of $\mathrm{HO}_{2} / \mathrm{H}_{2} \mathrm{O}_{2}$ and intermediate species in low and in- 1173 termediate temperature oxidation of dimethyl ether, Proc. Combust. Inst. 351174 (2015) 457-464.

[48] P. Dagaut, C. Daly, J. Simmie, M. Cathonnet, The oxidation and ignition of 1176 dimethylether from low to high temperature (500-1600K): Experiments and 1177 kinetic modeling, Symp. (Int.) Combust. 27 (1998) 361-369. 1178

[49] H.J. Curran, S.L. Fischer, F.L. Dryer, The reaction kinetics of dimethyl ether. II: 1179 Low-temperature oxidation in flow reactors, Int. J. Chem. Kinet. 32 (2000) 741- 1180 759.

[50] H. Guo, W. Sun, F.M. Haas, T. Farouk, F.L. Dryer, Y. Ju, Measurements of $\mathrm{H}_{2} \mathrm{O}_{2} 1182$ in low temperature dimethyl ether oxidation, Proc. Combust. Inst. 34 (2013) 1183 $573-581$.

[51] F. Herrmann, B. Jochim, P. Oßwald, L. Cai, H. Pitsch, K. Kohse-Höinghaus, Ex- 1185 perimental and numerical low-temperature oxidation study of ethanol and 1186 dimethyl ether, Combust. Flame 161 (2014) 384-397. of the low-temperature dimethyl ether oxidation in an atmospheric pressure 1189 laminar flow reactor, Proc. Combust. Inst. 34 (2013) 771-778.

[53] K. Moshammer A.W. Jasper, D.M. Popolan-Vaida, A. Lucassen, P. Diévart, H. Se- 1191 lim, A.J. Eskola, C.A. Taatjes, S.R. Leone, S.M. Sarathy, Y. Ju, P. Dagaut, K. Kohse- 1192 Höinghaus, N. Hansen, Detection and identification of the keto-hydroperoxide 1193 $\left(\mathrm{HOOCH} \mathrm{OCHO}_{2}\right)$ and other intermediates during low-temperature oxidation of 1194 dimethyl ether, J. Phys. Chem. A 119 (2015) 7361-7374.

[54] K. Moshammer, A.W. Jasper, D.M. Popolan-Vaida, Z. Wang, V.S. Bhavani 1196 Shankar, L. Ruwe, C.A. Taatjes, P. Dagaut, N. Hansen, Quantification of the keto- 1197 hydroperoxide $\left(\mathrm{HOOCH}_{2} \mathrm{OCHO}\right)$ and other elusive intermediates during low- 1198 temperature oxidation of dimethyl ether, J. Phys. Chem. A 120 (2016) 7890- 1199 7901.

[55] A.J. Eskola, S.A. Carr, R.J. Shannon, B. Wang, M.A. Blitz, M.J. Pilling, P.W. Seakins, 1201 S.H. Robertson, Analysis of the kinetics and yields of $\mathrm{OH}$ radical production 1202 from the $\mathrm{CH}_{3} \mathrm{OCH}_{2}+\mathrm{O}_{2}$ reaction in the temperature range 195-650 K: an ex- 1203 perimental and computational study, J. Phys. Chem. A 118 (2014) 6773-6788. 1204

[56] A.S. Tomlin, E. Agbro, V. Nevrlý, J. Dlabka, M. Vašinek, Evaluation of com- 1205 bustion mechanisms using global uncertainty and sensitivity analyses: a case 1206 study for low-temperature dimethyl ether oxidation, Int. J. Chem. Kinet. 461207 (2014) 662-682.

[57] A. Rodriguez, O. Frottier O. Herbinet, R. Fournet, R. Bounaceur, C Fittschen, 1209 F. Battin-Leclerc, Experimental and modeling investigation of the low- 1210 temperature oxidation of dimethyl ether, J. Phys. Chem. A 119 (2015) 7905- 1211 7923.

[58] X. Jiang, F. Deng, F. Yang, Y. Zhang, Z. Huang, High temperature ignition delay 1213 time of DME/n-pentane mixture under fuel lean condition, Fuel 191 (2017) 77- 1214 86.

[59] M. Eyidogan, A.N. Ozsezen, M. Canakci, A. Turkcan, Impact of alcohol-gasoline 1216 fuel blends on the performance and combustion characteristics of an SI engine, 1217 Fuel 89 (2010) 2713-2720.

[60] L.R. Cancino, M. Fikri, A.A.M. Oliveira, C. Schulz Measurement and chemical ki- 1219 netics modeling of shock-induced ignition of ethanol-air mixtures, Energy Fu- 1220 els 24 (2010) 2830-2840.

[61] F.M. Haas, M. Chaos, F.L. Dryer, Low and intermediate temperature oxidation of 1222 ethanol and ethanol-PRF blends: an experimental and modeling study, Com- 1223 bust. Flame 156 (2009) 2346-2350.

[62] G. Mittal, S.M. Burke, V.A. Davies, B. Parajuli, W.K. Metcalfe, H.J. Curran, Au- 1225 toignition of ethanol in a rapid compression machine, Combust. Flame 1611226 (2014) 1164-1171.

[63] M.S. Graboski, R.L. McCormick, Combustion of fat and vegetable oil derived 1228 fuels in diesel engines, Prog. Energy Combust. Sci. 24 (1998) 125-164.

[64] Y. Zhang, H. El-Merhubi, B. Lefort, L. Le Moyne, H.J. Curran, A. Kéromnès, Prob- 1230 ing the low-temperature chemistry of ethanol via the addition of dimethyl 1231 ether, Combust. Flame 190 (2018) 74-86.

[65] C. Hemken, U. Burke, K.-F. Lam, D.F. Davidson, R.K. Hanson, K.A. Heufer, 1233 K. Kohse-Höinghaus, Toward a better understanding of 2-butanone oxidation: 1234 detailed species measurements and kinetic modeling, Combust. Flame 1841235 (2017) 195-207.

[66] M. Schent, Leon, K. Moshammer, P. Oßwald, T. Zeuch, L Seidel, F Mauss, 1237 K. Kohse-Höinghaus, Detailed mass spectrometric and modeling study of iso- 1238 meric butene flames, Combust. Flame 160 (2013) 487-503.

[67] L. Cai, A. Sudholt, D.J. Lee, F.N. Egolfopoulos, H. Pitsch, C.K. Westbrook, 1240 S.M. Sarathy, Chemical kinetic study of a novel lignocellulosic biofuel: Di- $n-1241$ butyl ether oxidation in a laminar flow reactor and flames, Combust. Flame 1242 161 (2014) 798-809. 
[68] A. Cuoci, A. Frassoldati, T. Faravelli, E. Ranzi, OpenSMOKE++: An objectoriented framework for the numerical modeling of reactive systems with detailed kinetic mechanisms, Comput. Phys. Commun. 192 (2015) 237264.

[69] S.L. Fischer, F.L. Dryer, H.J. Curran, The reaction kinetics of dimethyl ether. I: High-temperature pyrolysis and oxidation in flow reactors, Int. J. Chem. Kinet. 32 (2000) 713-740.
[70] Z. Wang, X. Zhang, L. Xing, L. Zhang, F. Herrmann, K. Moshammer, F. Qi, 1251 K. Kohse-Höinghaus, Experimental and kinetic modeling study of the low- and 1252 intermediate-temperature oxidation of dimethyl ether, Combust. Flame 1621253 $\begin{array}{ll}\text { (2015) 1113-1125. } & 1254\end{array}$

[71] S. Xu, R.S. Zhu, M.C. Lin, Ab initio study of the $\mathrm{OH}+\mathrm{CH}_{2} \mathrm{O}$ reaction: the effect 1255 of the $\mathrm{OH} \cdot \mathrm{OCH}_{2}$ complex on the H-abstraction kinetics, Int. J. Chem. Kinet. 381256 (2006) 322-326. 